Article

\title{
Carbonaceous Aerosols Collected at the Observatory of Monte Curcio in the Southern Mediterranean Basin
}

\author{
Mariantonia Bencardino ${ }^{1, *}$, Virginia Andreoli ${ }^{1}$, Francesco D'Amore ${ }^{1}$, Francesco De Simone ${ }^{1}$, \\ Valentino Mannarino ${ }^{1}$, Jessica Castagna ${ }^{2}$, Sacha Moretti ${ }^{1}$, Attilio Naccarato ${ }^{1}{ }^{1}$, \\ Francesca Sprovieri ${ }^{1}$ and Nicola Pirrone ${ }^{1}$
}

1 Institute of Atmospheric Pollution of the National Research Council of Italy (IIA-CNR), Division of Rende, 87100 Cosenza, Italy; virginia.andreoli@iia.cnr.it (V.A.); f.damore@iia.cnr.it (F.D.A.);

f.desimone@iia.cnr.it (F.D.S.); v.mannarino@iia.cnr.it (V.M.); sacha.moretti@iia.cnr.it (S.M.);

a.naccarato@iia.cnr.it (A.N.); f.sprovieri@iia.cnr.it (F.S.); nicola.pirrone@iia.cnr.it (N.P.)

2 Institute of Methodologies for Environmental Analysis of the National Research Council of

Italy (IMAA-CNR), Tito Scalo, 85100 Potenza, Italy; jessica.castagna@imaa.cnr.it

* Correspondence: bencardino@iia.cnr.it

Received: 1 August 2019; Accepted: 25 September 2019; Published: 2 October 2019

\begin{abstract}
This work provides the first continuous measurements of carbonaceous aerosol at the Global Atmosphere Watch (GAW) Monte Curcio regional station, within the southern Mediterranean basin. We specifically analyzed elemental carbon (EC) and organic carbon (OC) concentrations in particulate matter (PM) samples, collected from April to December during the two years of 2016 and 2017. The purpose of the study is to understand the behavior of both PM and carbonaceous species, in their fine and coarse size fraction, along with their seasonal variability. Based on 18 months of observations, we obtained a dataset that resulted in a vast range of variability. We found the maximum values in summer, mainly related to the enhanced formation of secondary pollutants owing to intense solar radiation, also due to the high frequency of wildfires in the surrounding areas, as well as to the reduced precipitation and aerosol-wet removal. We otherwise observed the lowest levels during fall, coinciding with well-ventilated conditions, low photochemical activity, higher precipitation amounts, and less frequency of Saharan dust episodes. We employed the HYSPLIT model to identify long-range transport from Saharan desert. We found that the Saharan dust events caused higher concentrations of PM and OC in the coarser size fraction whereas the wildfire events likely influenced the highest PM, OC, and EC concentrations we recorded for the finer fraction.
\end{abstract}

Keywords: carbonaceous species; Mediterranean basin; wildfires; Saharan dust; seasonal variability

\section{Introduction}

Detailed knowledge of particulate matter (PM) physicochemical properties in the last few decades has become increasingly important because size and composition characterization of atmospheric particles is relevant to atmospheric process modeling [1] and for environmental control purposes [2]. Due to its wide implications, PM constitutes a growing challenge as it is a complex subject of study. The understanding of its atmospheric evolution is indeed made difficult by the wide number of emission sources and by the numerous physical and chemical processes that are correlated to local, mesoscale, and synoptic meteorological conditions, which in turn influence the PM complex chemical composition.

Among various elements, the carbonaceous fraction is an important component of particulate matter (PM), generally ranging between 20 and $50 \%$ of PM mass [3,4]. Due to both climate and human health implications, there is growing scientific interest in understanding and developing processes involving atmospheric carbon [5]. 
Carbonaceous material is usually divided in two fractions: (1) Elemental carbon (EC)-sometimes referred to as black carbon (BC) or graphitic carbon, and (2) organic carbon (OC). The terminology of $\mathrm{EC}$ and $\mathrm{BC}$ has originated from their measurement technique. The $\mathrm{BC}$ refers to the light-absorbing part of the carbonaceous aerosols and is determined using an optical method. In contrast, the EC is a refractory constituent of the aerosols and is determined using a thermo-optical technique under oxidizing condition [6]. EC is a primary pollutant formed in combustion processes whereas OC is a complex mixture of many groups of compounds originating from primary sources and secondary formation processes [7]. The OC is mainly composed of primary organic carbon (POC) and secondary organic carbon (SOC), which is produced by photochemical reactions from pollutants. The components of OC are very complex and rich in toxic substances, and have the potential to cause great harm to human health [8,9] In spite of the importance of the carbonaceous species, detailed studies on their characterization and variability are still scarce [10]. Most of the studies performed in the Mediterranean area are based on samplings carried out at coastal sites, with strong influences from the continental meteorology and from anthropogenic sources; thus, regional background and remote sites are essential for the study of natural sources and to obtain information on the Mediterranean basin [11-14]. Recent results of a European project [15] further evidence that the spatial variability and the sources of $\mathrm{PM}_{2.5}$ in southern Europe are less known with respect to $\mathrm{PM}_{10}$ because the fine fraction is not widely measured. Therefore, there is also limited information on spatial and temporal variability of coarse fraction $\left(\mathrm{PM}_{2.5-10}\right)$, often linked to local and natural sources [16]. Therefore, further research efforts are needed to investigate long-term trends of sources of fine and coarse PM fractions in this area for air quality applications, for management of health risks, and for analysis of PM impact on climate change in the Mediterranean basin.

In this context, we conducted an intensive measurement campaign at the Monte Curcio (MCU) Environmental-Climate Observatory, recently built in Southern Italy (in Calabria), and managed by the Institute of Atmospheric Pollution of the National Research Council (IIA CNR). We collected daily simultaneous samples of $\mathrm{PM}_{2.5}$ and $\mathrm{PM}_{10}$ for almost two years (2016-2017), and then analyzed the sampled filters, via a thermo-optical method, to characterize their carbonaceous component. Carbonaceous species were determined separating EC, mainly of primary origin from combustion sources, and OC, having a primary and secondary component. We explored the seasonal variability of both aerosols and carbonaceous species in respect to changes in meteorological conditions and source influences. We also examined the different behavior of fine and coarse size fractions for both PM, EC, and OC species. This work thus responds precisely to the need of providing, for the first time to our knowledge, more information on EC and OC concentration measurements at a rural background site in the southern Mediterranean basin.

\section{Methods and Measures}

\subsection{Sampling Station and Particulate Collection}

The Environmental-Climate Observatory of Monte Curcio (MCU) $\left(39.2^{\circ} \mathrm{N} 16.2^{\circ} \mathrm{E} ; 1796 \mathrm{~m}\right.$ a.s.l.) was activated in the framework of the PON Project I-AMICA (Infrastructure of High Technology for Integrated Climate and Environmental Monitoring, available online: http://www.i-amica.it/) and it has been operating since 2015. It is a regional station of the Global Atmosphere Watch (GAW) program, established by the World Meteorological Organization (WMO)—a United Nations agency-aimed to systematic long-term monitoring of atmospheric chemical and physical parameters at global scale [17]. Figure 1 shows the coordinates of our sampling site. Located within the Sila National Park, within an extended plateau of tens of $\mathrm{km}$ at a mean altitude of about 1200-1300 m, the station is not influenced by local anthropogenic sources. However, as reported in [18], there are some important urban centers (the cities of Cosenza and Rende) at tens of kilometers far from our MCU station. For this reason, our monitoring site cannot be defined as a remote, but as a rural high-altitude monitoring station. The strategic location of MCU site is due to a mixing of geographical locations, in the middle in the 
Mediterranean, and altitude, allowing the advantage to intercept long-range transported air masses. Unfortunately, at the MCU station we did not have any specific instrumental data to characterize the site in relation to the Planetary Boundary Layer (PBL). Moreover, the orographically complex region of the Sila Massif would require a highly resolved model that captures the main topography [18], and this did not allow us to reliably use data from reanalysis modelling to characterize the site. However, since the height of the site had a relatively small height difference from surrounding plateau, following the teaching of Coen et al. 2018 [19], we qualitatively concluded that the site is influenced by PBL air masses. Despite this, especially during the night and the cold season, MCU is likely to intercept air masses from above the PBL [19].

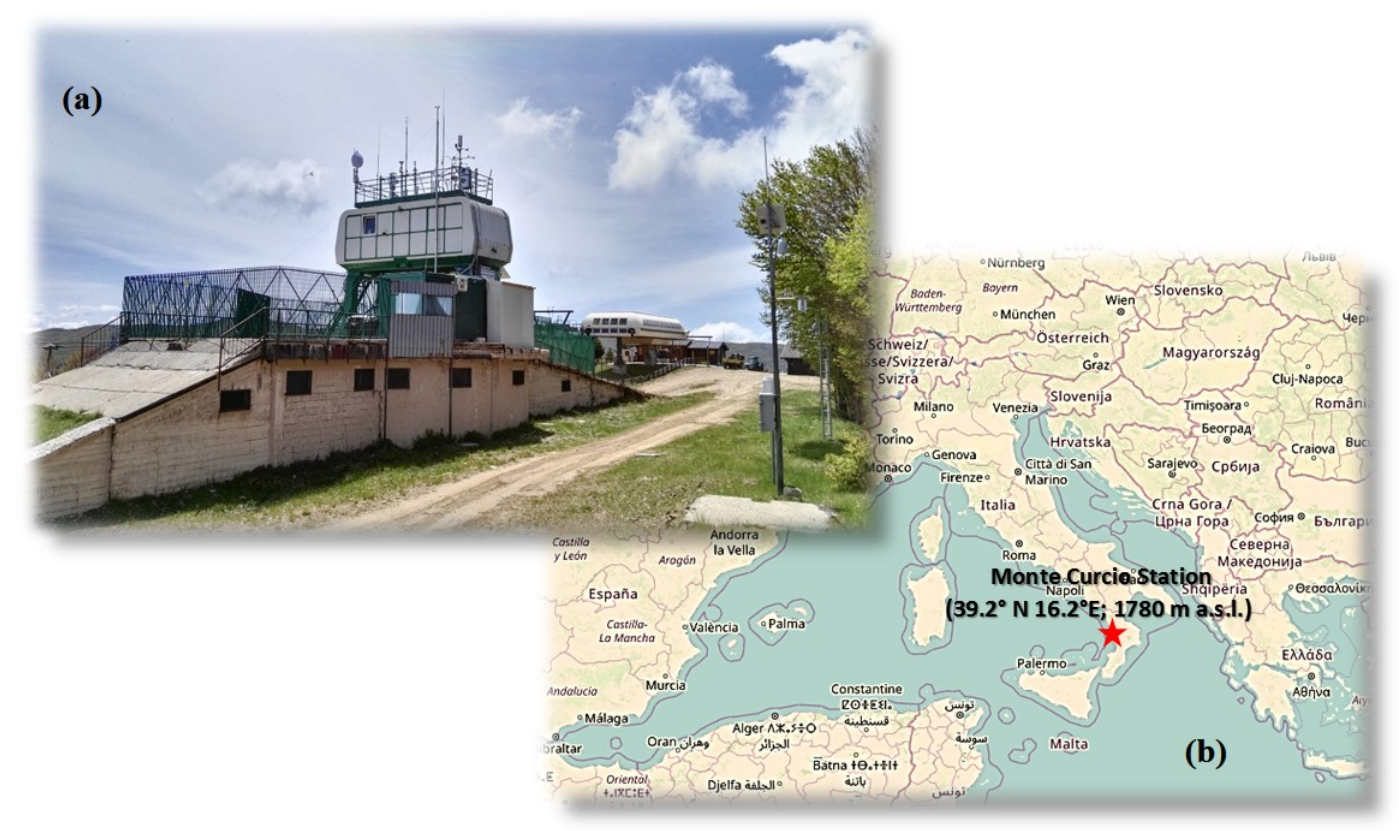

Figure 1. Context and geographical location of the Monte Curcio (MCU) Observatory. Pictures are provided by (a) Valentino Mannarino, and (b) Images@ OpenStreetMap contributors (https: //www.openstreetmap.org/copyright).

Among various atmospheric monitoring instruments, the station is equipped with a dual channel sequential sampler (SWAM 5a Dual Channel Monitor; FAI Instruments, Fonte Nuova, Rome-IT)) which is compliant with EU equivalence criteria for $\mathrm{PM}_{10}$ and $\mathrm{PM}_{2.5}$ measurements against the reference methods [20]. The SWAM 5a Dual Channel sampler automatically provides simultaneous sampling and PM mass measurement on two filter membranes by using the $\beta$-attenuation method. We specifically used this instrument at a flow-operating rate of about $2.3 \mathrm{~m}^{3} / \mathrm{h}$ to simultaneously collected $\mathrm{PM}_{10}$ and $\mathrm{PM}_{2.5}$ samples. We set the sampling start at midnight with a sampling duration of $24 \mathrm{~h}$. As a substrate for $\mathrm{PM}_{10}$ and $\mathrm{PM}_{2.5}$ collection, we used 47-mm Whatman Q-grade quartz microfiber filters because it is thermally stable and it is recommended in the scientific community for the determination of EC/OC [21,22]. The principle of the 3 -attenuation method is such: Each white filter, before collecting PM, is placed between one radioactive source inside the instrument that emits electrons (beta radiation) and a detector (Geiger-Muller counter) that measures the radiation passing through the filter "clean" (white measure). Subsequently, a constant airflow for $24 \mathrm{~h}$ passes through the filter where the suspended particulate is deposited; at the end of the period of sampling the filter is repositioned under the radioactive source and the Geiger counter measures again the radiation that passes through the sampled filter. Since the particulate has settled on surface of the filter, the intensity of the beta radiation will result attenuated compared to the white measure. The difference between the two measures is proportional to the $\mathrm{PM}_{10} / \mathrm{PM}_{2.5}$ mass concentrations in the ambient air for the $24 \mathrm{~h}$ of sampling. By using this method, in total, we gained daily samples for $\mathrm{PM}_{10}$ for $\mathrm{PM}_{2.5}$ in the 
period from April to December, for both the two years of observation: 2016 and 2017. From January to March we did not carry out PM collection. During this winter period, we experienced the lowest temperature of the year (see Figure 2), with some degrees below zero, causing some technical problems in correct sampling.

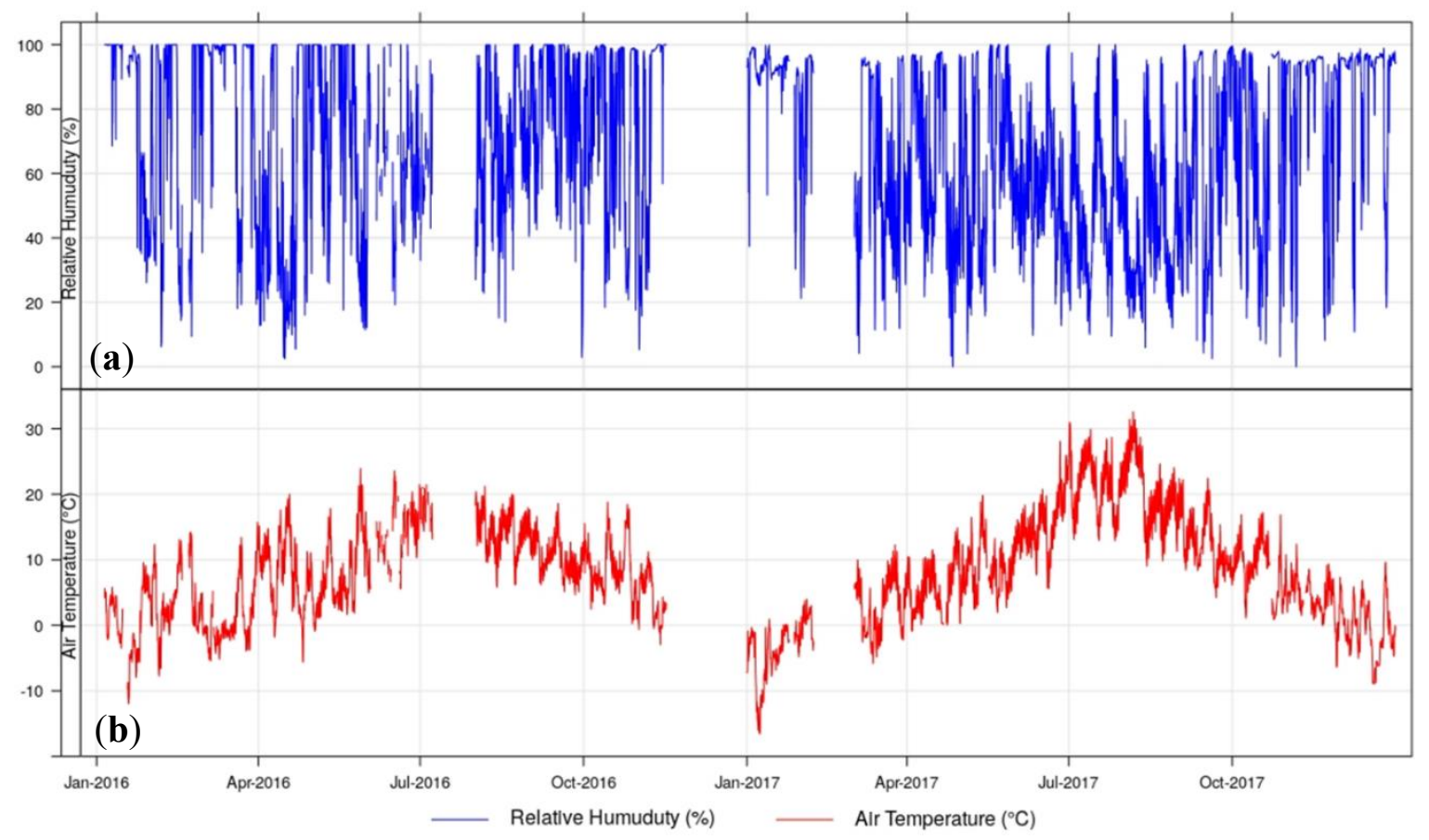

Figure 2. Time series of (a) relative humidity (\%) and (b)air temperature $\left({ }^{\circ} \mathrm{C}\right)$ recorded at the MCU Observatory.

The Observatory is further equipped with a meteorological station (Lastem LSI) by which we recorded the local meteorological parameters such as relative humidity (with respect to liquid water; $\mathrm{RH}$ ), air temperature (T), atmospheric pressure (P), wind speed (WS), and wind direction (WD). Time resolution for these meteorological parameters is set to $1 \mathrm{~min}$. Unfortunately, our rain gauge did not operate properly throughout our work experiment, therefore, we did not collect precipitation accumulation data from our meteorological station. However, in order to discriminate between dry and wet periods in our sampling area, we used rainfall data obtained from another weather station located at Monte Curcio but managed by the Cosenza Meteo Association (http: //www.cosenzameteo.it/report-noaa-camigliatello-silano/).

\subsection{EC/OC Measurements}

After collection of simultaneous $\mathrm{PM}_{10}$ and $\mathrm{PM}_{2.5}$ samples, we used one quarter of each sampled filter to obtain a punch size $\left(1 \mathrm{~cm}^{2}\right)$ for the determination of OC and EC concentrations via the thermo-optical method (TOT). We used a Sunset Laboratory OC/EC analyzer [23] following the EUSARII-2 protocol, which is recognized as the European standard thermal protocol for the measurements of TC, OC, and EC in both $\mathrm{PM}_{10}$ and $\mathrm{PM}_{2.5}$ samples [24]. We performed the analysis of Total Carbon (TC $=\mathrm{OC}+\mathrm{EC}$ ) on all filters, pre-fired for $2 \mathrm{~h}$ at $700{ }^{\circ} \mathrm{C}$, in order to remove any residual carbon contamination, and then implementing the EUSAAR-2 temperature protocol [25]. To ensure the accuracy of the OC and EC results, we calibrated periodically the analyzer with an external standard containing known amounts of carbon (e.g., sucrose). Therefore, we used standard sucrose solutions covering the operating range of samples concentrations for the 3-point calibration of the Sunset OC/EC analyzer instrument and ongoing quality control. In particular, we pipetted 2.5, 5, $10 \mu \mathrm{L}$ from aqueous solutions of sucrose (Sunset Laboratory Sucrose Standard $2.198 \mathrm{mg} \mathrm{C} / \mathrm{mL}$ ) on 
$1.0 \mathrm{~cm}^{2}$ prebaked quartz-fiber filters. We inserted the wet samples in the analyzer sample holder and dried during $2 \mathrm{~min}$ at $70{ }^{\circ} \mathrm{C}$, under a helium stream, before initiating the total carbon combustion temperature program. This procedure allows us to update the calibration constant and perform a full calibration curve on a regular basis. Following the same procedure of the exposed samples, we also analyzed blank filters for correcting the measured concentrations. We obtained concentrations of the different species after subtraction of the average level present in the blank samples. We found negligible EC concentrations in blank filters; however, we observed contamination for OC with an average correction that was about $7 \%$. We analyzed OC and EC analytical uncertainties by calculations recommended by the instrument manufacturer [23], finding out relative standard deviations less than $5 \%$. In this study, we additionally quantified the Secondary Organic Carbon (SOC) concentration by using the methodology proposed by Castro et al. [26] and already applied in other studies [27-32]. Following this approach, we estimated the concentration of SOC from the equation reported below:

$$
\mathrm{SOC}=\mathrm{OC}_{\text {total }}-(\mathrm{OC} / \mathrm{EC})_{\text {minimum }} \times \mathrm{EC}
$$

This commonly used method for the indirect evaluation of SOC in atmospheric particles, has the advantage of simplicity and low cost, and is based on the minimum values of OC/EC ratios, considering that those represented samples contain exclusively primary carbonaceous aerosol from fossil fuel combustion $[26,32,33]$.

\subsection{Data Processing and Supporting Tools}

For the PM collection, we checked the operational parameters of our sampler instrument such as flow rates, temperatures, pressures, and humidity. We visually checked the raw data for plausibility and then removed outliers resulting from malfunctioning from the data set. In total, we gained 384 samples (384 for $\mathrm{PM}_{10}$ and 384 for $\mathrm{PM}_{2.5}$ ) in the period from April to December for both the years 2016 and 2017. Since in our work we are interested in understanding the different behavior of fine and coarse particles fraction, we calculated $\mathrm{PM}_{2.5-10}$ (particulate matter with mass median aerodynamic diameter $>2.5 \mu \mathrm{m}$ to $<10 \mu \mathrm{m}$; coarse) concentrations by subtracting $\mathrm{PM}_{2.5}$ from $\mathrm{PM}_{10}$ concentrations. We followed the same procedure for carbonaceous species to obtain the $\mathrm{EC}_{2.5-10}$ and $\mathrm{OC}_{2.5-10}$ size fractions. We considered as valid only EC and $\mathrm{OC}$ data passing the quality assurance and quality control checks suggested by the instrument manufacturer [23] and following the guidance of the European Standard [24] and used them for all the calculations and statistical analyses. We studied temporal trends (monthly and seasonal) of both PM and carbonaceous species, in their fine and coarse size fractions, using descriptive statistics by Excel 2013 Software. In particular, in this work we showed the monthly trends by using the box-and-whiskers plot, in which each box includes the mean (midline), 25th and 75th percentiles (box edges), 5th and 95th percentiles (whiskers). Regarding the meteorological parameters, we converted all of the raw data into hourly averages, which we considered valid, if at least $66 \%$ of the data were available. We then analyzed seasonal as well as hourly-averaged values from our measured meteorological parameters by using, in this case, the R framework. To show how wind speed and wind direction conditions varied at the MCU Observatory, we used a wind rose representation, which is a useful way of summarizing this kind of meteorological data. We used our WS and WD hourly data as input to the "windRose" function of the R package called "openair" [34]. The "windRose" function can plot wind roses in a variety of ways: Summarizing all available wind speed and wind direction data, plotting individual wind roses by year, month or season. We considered the latter to show how wind conditions varied by season at MCU station. To identify the occurrence at MCU of some natural sources, such as wildfires and Saharan dust, we used the guidelines adopted by the European Commission for evaluating exceedances attributable to natural sources under the Directive 2008/50/EC on ambient air quality and cleaner air for Europe [35]. These European guidelines identify satellite images and back-trajectories analysis as useful tools in determining the impact of these kind of natural sources. A large number of previous studies used this methodology [36-40]. In our 
study, for each day of our sampling collection and with our monitoring site as the starting point, we carried out a back-trajectory analysis. We established the trajectory arrival height at the elevation of the MCU station, $1796 \mathrm{~m}$ above ground level. Then, we calculated four days' back-trajectories, by means of the Hybrid Single-Particle Lagrangian Integrated Trajectories (HYSPLIT4) trajectory model [41], and using meteorological data supplied by the US National Climatic Data Center. We used the Global Data Assimilation (GDAS) set as meteorological input. We carried out a further investigation, by using, as suggested by the same European guidelines [35], additional tools such as numerical models and satellite images. In particular, the interpretation of the sort of aerosols was supported by the Navy Aerosol Analysis and Prediction System (NAAPS) developed by the Naval Research Laboratory (NRL) (http://www.nrlmry.navy.mil/aerosol). As reported elsewhere [37,42], the dust and smoke concentration NAAPS-based maps were useful to confirm episodes of wildfire events or the transport from North Africa, respectively. We also used MODIS true-color images (http://rapidfire.sci.gsfc.nasa.gov/) (not shown here) to identify the origins and the extension of fire events. We also obtained specific locations and daily total fire hotspots over the area surrounding our monitoring station from the Fire Information for Resource Management System (FIRMS) (http://maps.geog.umd.edu/firms), which integrates remote sensing and Geographical Information System (GIS) technologies to deliver global Moderate-resolution Imaging Spectroradiometer (MODIS) hotspot/fire locations (not shown here).

\section{Results}

\subsection{Meteorological Variability at the MCU Station}

At the MCU station, we measured meteorological parameters, including RH T, WS, WD, and P, with the accuracy reported in Table S1. We summarized the main descriptive statistics (min, mean and max) of each of the above-mentioned meteorological parameters in Table S2 where results are split by seasonal periods of our observations. However, to better analyze the meteorological conditions at MCU, we reported in Figure 2 the hourly time series, over 2016 and 2017, of RH and T. This plot shows for RH minimum monthly values (below 50\%) in August 2017, and maximum monthly values (up to $80 \%$ ) in January, February, November, and December, for both the year 2016 and 2017. In average terms $\mathrm{RH}$ showed a higher level (76.8\%) in fall, while in spring and summer it was around $61 \%$ By looking at Figure 2, we can also observe that $\mathrm{T}$ exhibited an opposite trend, in respect to $\mathrm{RH}$, with the highest values (over than $10^{\circ} \mathrm{C}$ ) recorded from July until September, and peaking around July and August. Summer 2017 was exceptionally hot, having the hourly temperatures reached values above than $30^{\circ} \mathrm{C}$. The colder temperatures were recorded from January to March, and then from October to December, with the minimum (under $-10^{\circ} \mathrm{C}$ ) recorded in January. For $\mathrm{T}$, we found a seasonal trend showing the highest averaged values in summer $\left(15.7^{\circ} \mathrm{C}\right)$, followed by spring $\left(9.6^{\circ} \mathrm{C}\right)$ and then by fall $\left(5.1^{\circ} \mathrm{C}\right)$. Regarding WS and WD data, we used them as input to compute the seasonal wind roses reported in Figure 3. We obtained them by using the "windRose" function of the R package, useful to plot wind speed/direction frequencies. In Figure 3, wind speeds are split into four intervals, shown by the scale in each panel. The grey circles show the $\%$ frequencies. Wind direction indicates from where the wind is blowing. We found that at MCU station the prevailing wind direction was westerly. Wind rose for spring and summer show similar prevailing wind direction from west (W) and south-west (SW), even if during summer the frequency associated with the latter direction showed a larger frequency associated with the highest WS values. We can deduce that these wind conditions favored, with larger intensity during spring the advection, of PM from sources located at SW in respect to MCU location. During fall the wind conditions at MCU did not show any prevailing direction. The wind rose in Figure $3 c$ reports higher wind direction frequencies for both southernly (S) westerly $(W)$ and easterly (E) also associated with more intense winds. Therefore, during fall season the meteorological conditions were more unstable, thus favoring dispersion and dilution of aerosol particles and preventing local accumulations [43-45]. 

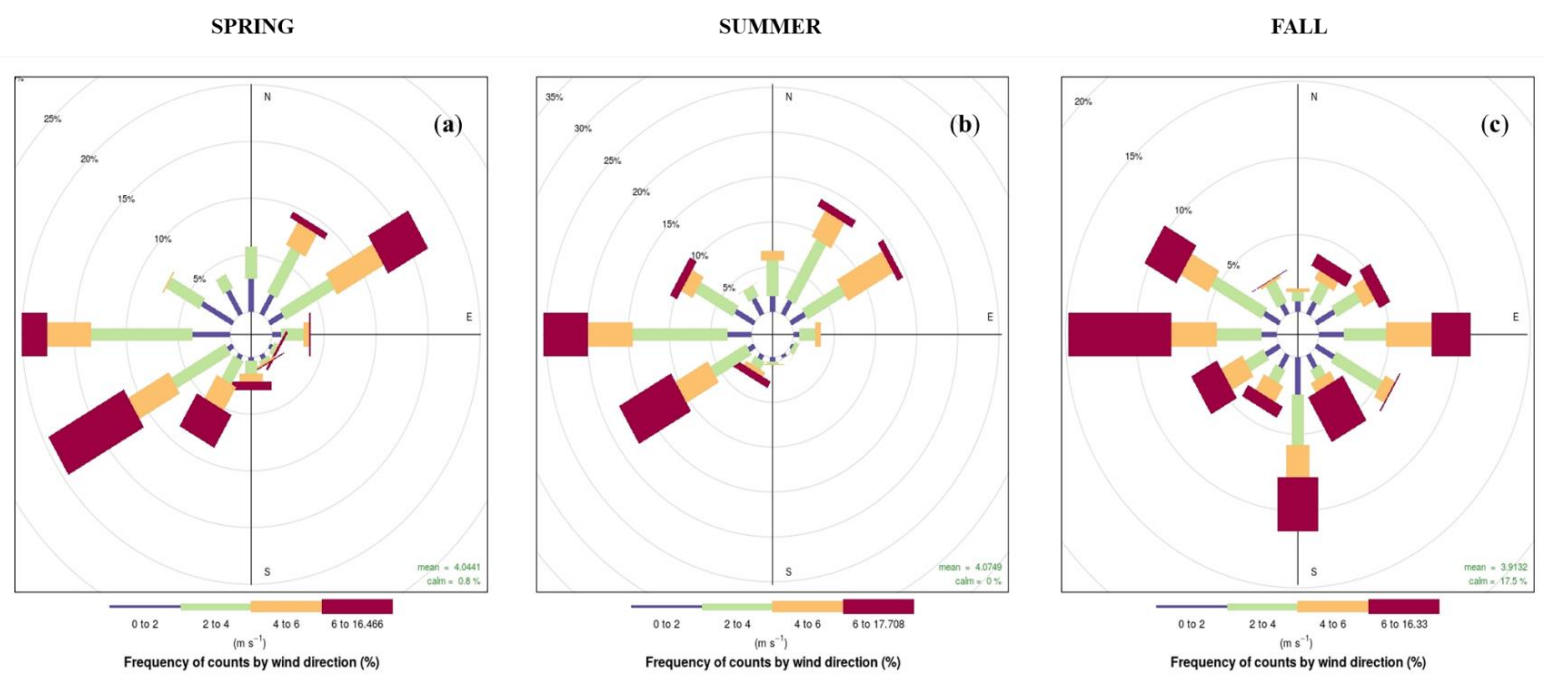

Figure 3. Seasonal wind roses for: (a) spring; (b) summer; and (c) fall period over the two years (2016-2017) of our measurements. Wind speeds are split into the intervals shown by the scale in each panel. The grey circles show the $\%$ frequencies.

\subsection{PM Levels and Size Distribution}

During our sampling campaign at MCU station, the PM collection was carried out from April to December, for both 2016 and 2017. In total we obtained the same number $(n=384)$ of sampled filters for both $\mathrm{PM}_{2.5}$ and $\mathrm{PM}_{10}$ aerosol size fractions. The average concentrations were $8.8 \pm 6.5 \mu \mathrm{g}$ $\mathrm{m}^{-3}$ for $\mathrm{PM}_{2.5}$, and $16.7 \pm 19.0 \mu \mathrm{g} \mathrm{m}^{-3}$ for $\mathrm{PM}_{10}$. These values are similar to those recorded in other high mountain sites and to those available at rural background stations across the Mediterranean basin (see Table S3 for station names, coordinates, and references). The daily $\mathrm{PM}_{10}$ concentration was found 16 times ( $4 \%$ over the sampling period) above the EU limit value for the protection of human health, which is equal to $50 \mu \mathrm{g} \mathrm{m}^{-3}$, as set in the European Directive on ambient air quality (Directive 2008/50/EC) [46].

However, our observations highlight a large variability, with mass concentrations ranging from 0.5 to $55.3 \mu \mathrm{g} \mathrm{m}^{-3}$ for $\mathrm{PM}_{2.5}$ and from 1.1 to $210.9 \mu \mathrm{g} \mathrm{m}{ }^{-3}$ for $\mathrm{PM}_{10}$, thus denoting the influence of different dynamics. In order to appreciate the different behavior of finer and coarser particles, as described in the Methods section, we obtained the concentration of $\mathrm{PM}_{2.5-10}$ as the difference between the recorded $\mathrm{PM}_{10}$ and $\mathrm{PM}_{2.5}$ levels. Over the whole period, and in average terms, we detected a prevalence of the fine mode (57\%) with respect to the coarse one. We also provided the monthly trends of both $\mathrm{PM}_{2.5}$ (fine) and $\mathrm{PM}_{2.5-10}$ (coarse) size fraction by means the box-and-wisher plots reported in Figure 4. These graphs in Figure 4 show that the average monthly values, for fine and coarse size fractions, approximately ranged in the same interval of values, going from $2.9 \mu \mathrm{g} \mathrm{m}^{-3}$ (in December 2017) to $19.6 \mu \mathrm{g} \mathrm{m}^{-3}$ (in August 2017 for the finer mode, and from $1.7 \mu \mathrm{g} \mathrm{m}^{-3}$ (in December 2017) to $18.7 \mathrm{\mu g} \mathrm{m}^{-3}$ (in April 2017) for the coarser one. The trend of each PM size fraction over the months of our observations was instead dissimilar. The fine fraction showed a clear feature with higher levels over the warmer months (April-August) in respect to those recorded in the colder ones (September-December). Differently, the coarser mode exhibited an indefinite trend with a peak value in April 2017. 


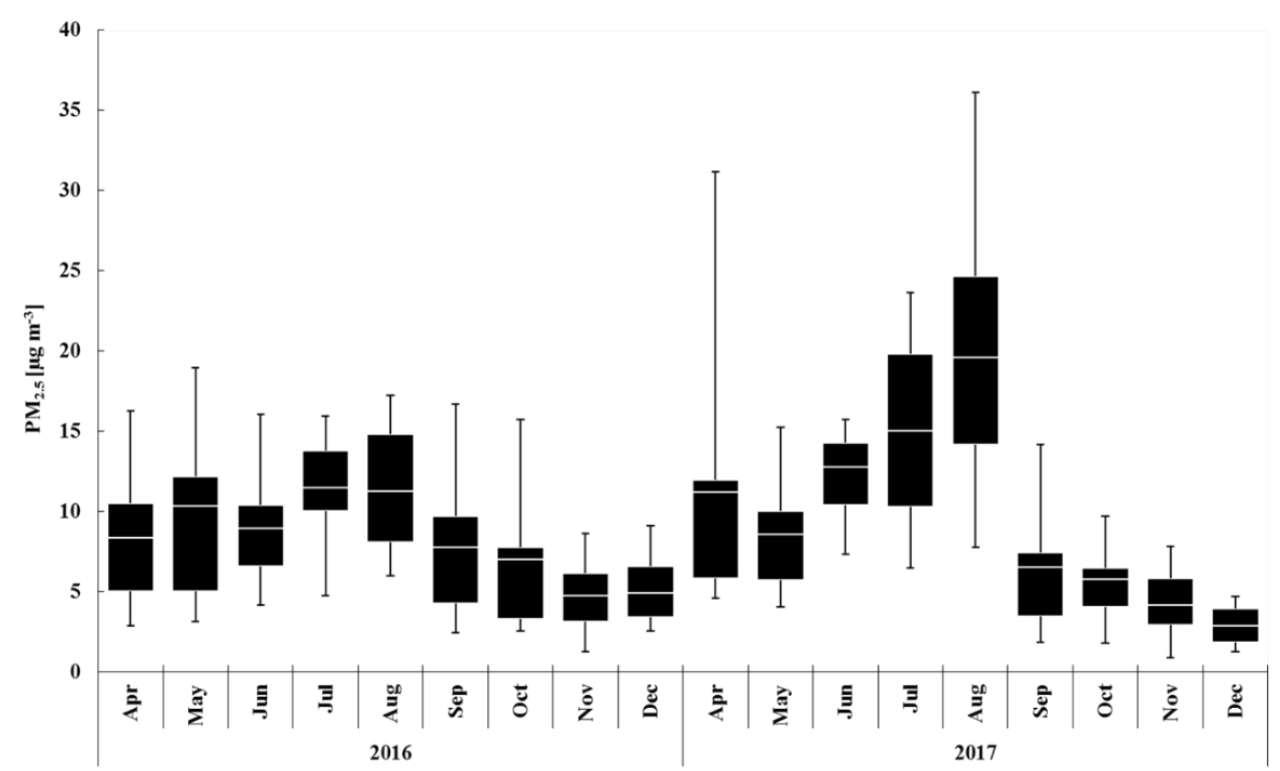

(a)

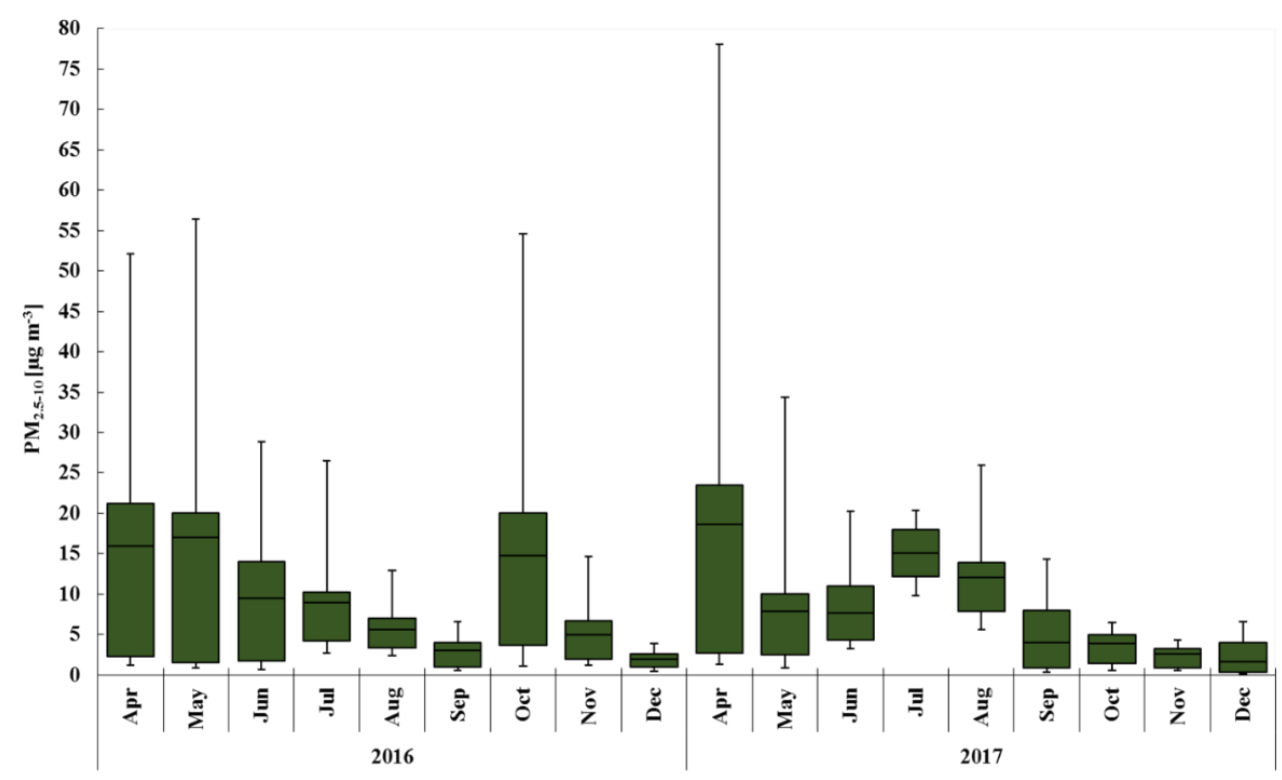

(b)

Figure 4. Monthly trend of (a) fine $\left(\mathrm{PM}_{2.5}\right)$, and $(\mathbf{b})$ coarse $\left(\mathrm{PM}_{2.5-10}\right)$ particles recorded at the $\mathrm{MCU}$ Observatory from April to December 2016 and from April to December 2017. Each box includes the mean (midline), 25th and 75th percentiles (box edges), 5th and 95th percentiles (whiskers).

\subsection{EC/OC Levels and SOC Content}

Over the whole period of our observations, we recorded EC mean values of $0.14 \pm 0.12 \mu \mathrm{g} \mathrm{m}^{-3}$ and $0.03 \pm 0.03 \mu \mathrm{g} \mathrm{m}^{-3}$, in the fine and coarse PM size fractions, and OC mean values of $1.2 \pm 1.6 \mu \mathrm{g}$ $\mathrm{m}^{-3}$, in the finer mode, and $0.5 \pm 0.5 \mu \mathrm{g} \mathrm{m}^{-3}$, in the coarser one. These values result slight lower than those available and recorded at the two high altitude remote sites in North Italy: Alpe San Colombano

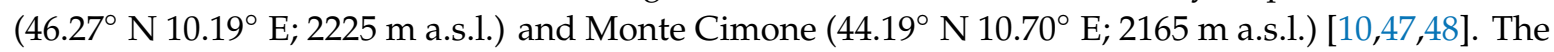
EC contributed with $0.5-2.4 \%$ (fine) and $0.02-2.4 \%$ (coarse) while the OC contribution was $3.7-28.8 \%$ (fine) and 3.8-22.8\% (coarse). In Figure 5, we summarized, on monthly basis and by box-and-whiskers plots, values recorded during the 2016 and 2017 sampling campaign, for EC and OC carbonaceous components, in both fine and coarse fractions. Results show a considerable variation of average values 
among the observed months. EC monthly averaged values specifically ranged from 0.02 to $0.47 \mu \mathrm{g}$ $\mathrm{m}^{-3}$ (fine) and from 0.02 to $0.06 \mu \mathrm{g} \mathrm{m}^{-3}$ (coarse) while the OC ones spaced from 0.2 to $5.6 \mu \mathrm{g} \mathrm{m}^{-3}$ (fine) and from 0.1 to $1.1 \mu \mathrm{g} \mathrm{m}^{-3}$ (coarse). For both OC and EC cases, similarly to PM mass concentration, the trend of the fine mode exhibited a maximum in August 2017 and was also featured by higher levels during the warmer period compared to lower ones observed from September till December. The coarse fraction, instead, showed a variable behavior over the months; however, the maximum values observed mainly during the warmer months were likely to have been influenced by a number of factors including: (1) A more stable planetary boundary layer over the summer [12,49]; (2) an enhanced formation of secondary pollutants owing to intense solar radiation; (3) the high frequency of wildfires in Mediterranean and surrounding areas; (4) increased anthropogenic pressure since the Sila National Park is a common tourist destination; and (5) reduced precipitation and aerosol wet removal. Otherwise we observed the lowest concentrations during the colder months, coinciding with well-ventilated conditions, low photochemical activity, and higher precipitation amounts. The $\mathrm{OC} / \mathrm{EC}$ ratio is strongly source dependent, and may provide a valuable tool to obtain information on the emission sources and the transformations of the carbonaceous aerosol [27]. Therefore, we reported also the OC/EC ratio on monthly basis and by box-and-whiskers plots (see Figure S1 in Supplementary Material). In general, the OC/EC ratio shows a large variability depending on the sources influencing specific sites, ranging from low values (about 1) in polluted environments to high values (up to 15) in rural/remote locations [50]. As expected, in our case the OC/EC ratio assumed very high levels, particularly in the coarse mode, whose value in average was equal to $28.1 \pm 40.4$. The OC/EC ratio assumed lower values in the fine mode, equal to $8.6 \pm 5.2$, as average over the whole period, but ranging anywhere from 1.3 to 52.8. These high OC/EC ratios can be attributed to low EC levels found in our rural environment [51] and also to the presence of source emissions of carbonaceous aerosols containing a higher OC/EC ratio, for example, wood combustion [52-54].
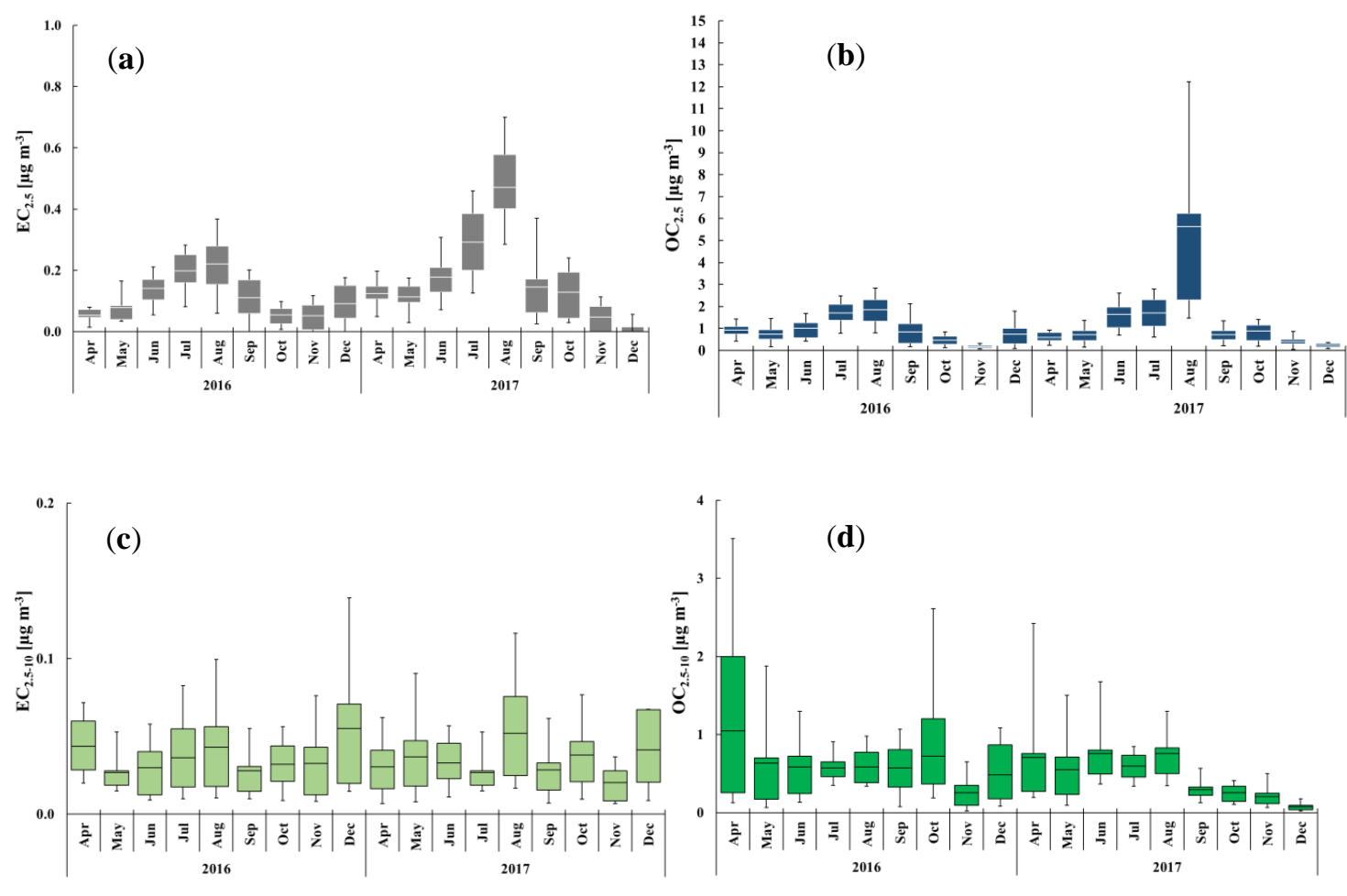

Figure 5. The upper side of this figure reports the monthly trend of (a) $\mathrm{EC}_{2.5}$ and (b) $\mathrm{OC}_{2.5}$ determined in the finer fraction. The bottom side shows the monthly trend for the carbonaceous species (c) $\mathrm{EC}_{2.5-10}$ and (d) $\mathrm{OC}_{2.5-10}$ revealed in the coarser fraction. Each box includes the mean (midline), 25th and 75th percentiles (box edges), 5th and 95th percentiles (whiskers). 
We additionally estimated the secondary organic carbon (SOC) concentrations by using the OC/EC minimum ratio method, as described in the Methods Section. Statistics regarding concentrations of SOC and its percentage contribution to the ambient OC, are summarized in Table S4, together with related PM, EC, and OC concentrations, for each of the three particulate size fractions $\left(\mathrm{PM}_{10}, \mathrm{PM}_{2.5}\right.$ (fine), and $\mathrm{PM}_{2.5-10}$ (coarse)). As summarized in Table S4, SOC was mainly present in the coarser fraction representing on average the $97 \%$ of total OC in the coarse mode and the $80 \%$ of total OC in the finer one. These percentages reveal a large contribution from SOC in part explained by the fact that our station is far from primary emission source. To understand how particulate and carbonaceous (EC and $\mathrm{OC}$ ) matter varied by season and by source we integrated the general overview herein presented with the analysis and discussion argued in the following paragraphs.

\subsection{Seasonal Variability}

Atmospheric aerosol concentrations are controlled by emission, transport, and deposition. Among meteorological variables, precipitation play a crucial role in their dispersion and diffusion. Based on a study of a historical set of meteorological data collected in the Calabria region (Southern Italy) the May-August period is reported as the average dry period, and the September-April period as the average wet period [55]. We also examined the rain data, recorded at a meteorological station located near our MCU station, and made available by the Cosenza Meteo Association (http: //www.cosenzameteo.it/report-noaa-camigliatello-silano/). We analyzed the rain data available for the last 10 years (from 2008-2018), with particular attention to years of our observations (2016-2017), getting confirmation of the period of wet (September-April) and dry (May-August) conditions for our area of investigations. We used these wet and dry periods as reference to discriminate measurements in our dataset and then evaluate the influence of precipitation on PM and carbonaceous levels recorded at MCU station (see Figure 6). As result, we obtained that aerosol particles, both PM and carbonaceous species, are removed by precipitation, decreasing in their concentration in correspondence of the wet season. The precipitation scavenging is, in fact, one of the most efficient cleaning mechanisms of the atmosphere [56]. This process is influenced by rain droplet size distribution, rain intensity and collision efficiency between particles and rain droplets $[6,57]$. We also observed that deposition increased with the decrease of the particle diameter [57]. There are different studies [58-62] where precipitation scavenging coefficients have been calculated showing that there is a linear relationship established between scavenging coefficient and rain intensity for different aerosol types.
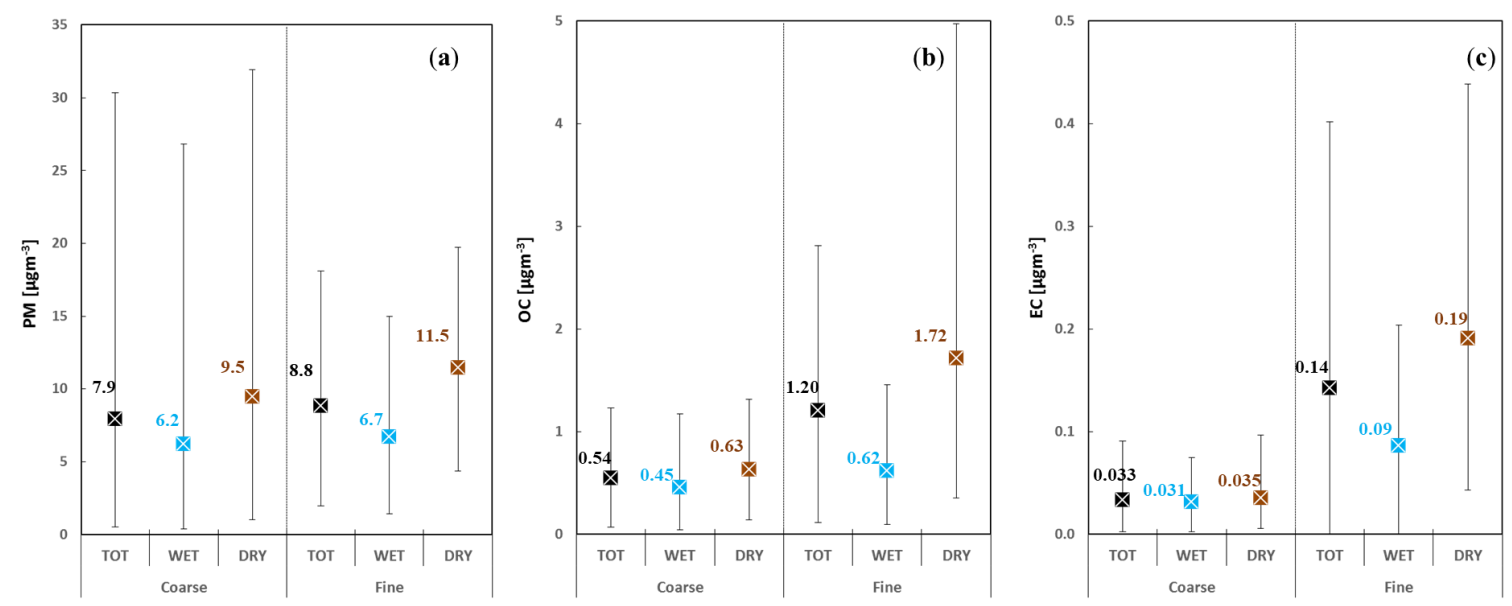

Figure 6. This figure shows mean levels (dots), 5th and 95th percentiles (whiskers) for: The whole dataset (black dots), for that containing only days being part of the wet season (blue dots), and that with days being part of the dry season (brown dots). We also distinguished between fine and coarse concentrations that are herein reported for (a) PM mass concentration; (b) OC; and (c) EC carbonaceous content. 
To further investigate the influence of local meteorology on the aerosol and carbon concentrations, we differentiated the main variables and parameters so far examined within three sub-groups, specifically referring to the period of: (1) Spring (April-May-June), (2) summer (July-August-September), and (3) fall (October-November-December). Measurements falling in the above-mentioned seasons were re-arranged accordingly and computation redone. We obtained descriptive statistics ( $\mathrm{min}$, mean, max, SD), for particulate and carbonaceous species levels in $\mathrm{PM}_{10}$, fine, and coarse size fractions, along with the OC/EC ratio, SOC calculation, and the percentage of SOC in OC for each of our three reference seasons (see Table S5). Comparing the results, it can be inferred that the largest values of both PM and carbonaceous species in the finer mode were measured in summer. Levels of $\mathrm{PM}_{10}$ and $\mathrm{PM}_{\text {coarse }}$ concentrations, as well as $\mathrm{OC}_{\text {coarse }}$ and $\mathrm{SOC}_{\text {coarse were instead found to }}$ be highest in spring. For the other variables, we in general found intermediate values in spring and the lowest values in fall. This seasonal trend is similar to that observed at the Monte Cimone high-elevated station where higher concentrations are typical of the summer period, while wintertime concentrations are extremely low (see Table S3 for station coordinates and references). This behavior may be considered dependent on the seasonality both of potential sources and of the dynamic properties of the PBL, which determine dilution or accumulation with mainly free tropospheric conditions characterizing the site during winter $[63,64]$. The $(\mathrm{OC} / \mathrm{EC})_{\min }$ ratios were determined separately for each available seasonal period. The ratios for $\mathrm{PM}_{10}$ were 1.6 (fall), 1.8 (spring), and 3.1 (summer). For the finer fraction the ratios were 1.3 (fall), 2.3 (spring), and 2.5 (summer), while for the coarser one, we obtained the following values: 0.1 (fall), 0.9 (spring), and 2.6 (summer). For this parameter, we can still recognize a seasonal variability with a minimum in fall and a maximum in summer. At our site, a higher summer contribution of OC may be expected considering the enhanced emission of VOCs from the vegetation and the increased photochemical activity promoting SOC formation. Even if we detected the major concentrations both of $\mathrm{OC}$ and SOC in the summer period, the percentage of SOC over OC resulted to be greater in fall, for which we had a contribution equal to $87 \%$ and $97 \%$ for fine and coarse fractions, respectively. In spring and summer, the percentage ( $\%$ SOC/OC) was around $66 \%$ and $75 \%$ in the fine particulate matter, and around $89 \%$ and $85 \%$ in the coarser fraction one. This fact may be due to low temperatures that favor a more effective formation of SOC via gas-to-particle conversion of oxidized products of volatile organic compounds present in the atmosphere [65].

\subsection{Influence of Wildfire Emissions and North African Mineral Dust}

As the MCU station is located in a rural area, a special attention was given to discriminate the influence of two of the main natural sources affecting the atmosphere of the Mediterranean basin: Wildfires emissions (WF), and Saharan dust coming from North Africa (NAF) [66]. As described in the methodology paragraph, the day-by-day identification was carried out by interpreting satellite maps, like those provided by both NAAPS, MODIS, and FIRMS tools, coupled with the analysis of air masses performed by the HYSPLIT modeling, which specifically allows visualizing the long-range transport of air masses and tracking the spatial sources. Days without any evidence of the above-mentioned sources were marked as background conditions (BKG). Table 1 reports the frequency by season of occurrence of the events above indicated. Results show a clear clustering of the three events (BKG, WF, NAF) among the seasons we observed at the MCU stations. During fall, both NAF and WF occurrences were rare, and almost $80 \%$ of the days of this period were marked as BKG. Otherwise, we found that WF events prevalently happened in summer with a percentage of occurrence equal to $70 \%$. NAF intrusions showed a quite larger presence (24\%) in the spring period even if BKG conditions were the majority with the $60 \%$. Over the whole period of our observations, we found a total number of 55 days affected by Saharan dust outbreaks, in line with other work done on this issue [67-69].

Figure 7 reports the HYSPLIT modelling results together with the NAAPS-based maps obtained for three distinct days we considered as representative for each of the three kind of events we are herein considering and analyzing. Specifically, Figure 7 refers to (a) 12 May 2016 for NAF dust intrusions 
(Episode I); (b) 7 August 2017 for WF occurrences (Episode II); and (c) 14 November 2016 for the BKG conditions (Episode III).

Table 1. Frequency occurrences of background (BKG) conditions, wildfire (WF) events; and North African Saharan dust (NAF) intrusions, by seasons observed at the MCU observatory.

\begin{tabular}{cccc}
\hline & Spring & Summer & Fall \\
\hline BKG & $60 \%$ & $29 \%$ & $80 \%$ \\
WF & $16 \%$ & $70 \%$ & $14 \%$ \\
NAF & $24 \%$ & $1 \%$ & $6 \%$ \\
\hline
\end{tabular}

\section{(a) NAF: 12 May 2016}
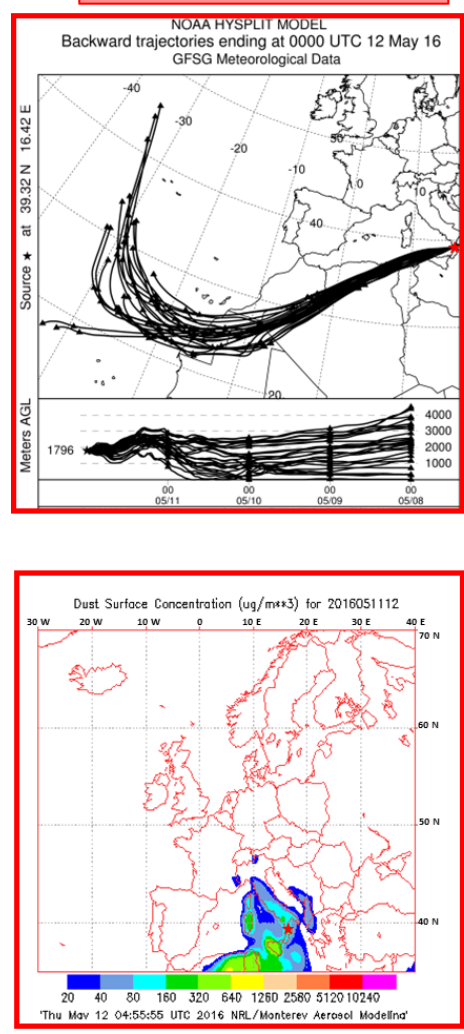

(b) WF: 7 Aug 2017
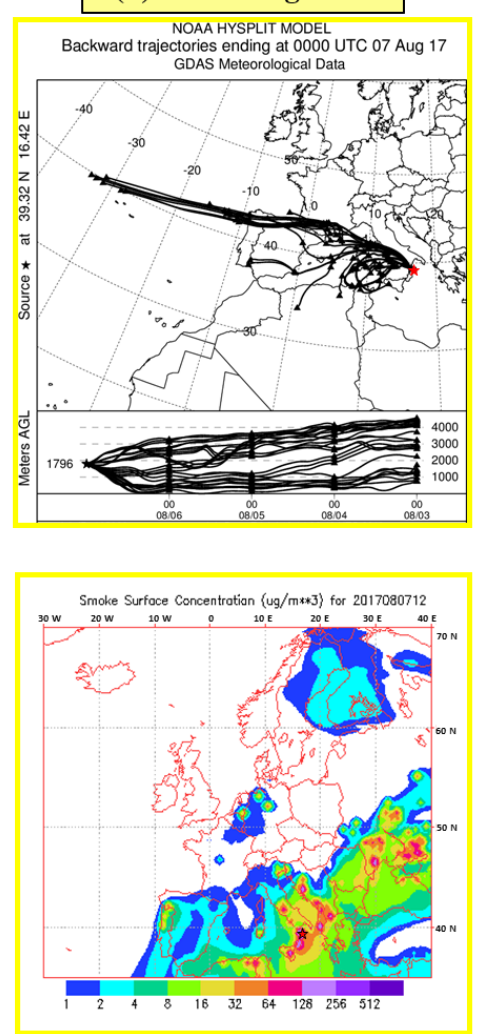

(c) BKG: 14 Nov 2016
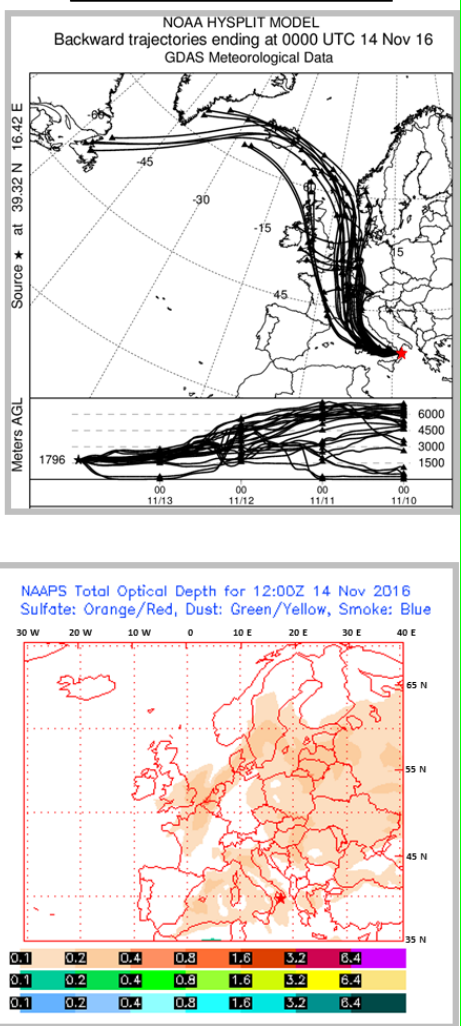

Figure 7. Upper panels report 4-days of backward trajectories provided by the Hysplit model for (a) 12 May 2016 for the North African Saharan dust (NAF) intrusions; (b) 7 August 2017 as representative of wildfire (WF) events; and (c) 14 November 2016, in representation of background (BKG) conditions. Lower panels report NAAPS-based maps showing, for the same days listed above: (a) dust surface concentrations; (b) smoke surface concentrations; and (c) total optical depth.

Episode I refers to 12 May 2016 and it is representative of dust intrusions coming from North Africa (NAF). Air masses reported in Figure 7a (upper side), show the typical path followed by air masses in conjunction with the presence of an anti-cyclone over the North Africa and characterized by winds blowing from south-west (SW) and able to transport Saharan dust over distance and inject them into the Mediterranean atmosphere. Regional studies carried out in the Mediterranean basin have shown that most of the dust-carrying winds have a westerly $(87 \%)$ or southwesterly $(61 \%)$ component (i.e., from North Africa). The intrusion of the air masses loaded with dust is evident in Figure 7a (lower side), where, as estimated by the NAAPS model, dust concentrations at ground level over our area corresponds to levels above $50 \mu \mathrm{g} \mathrm{m}^{-3}$. By the sampler in use at our MCU station, in correspondence of this Episode I, we recorded the largest value observed for $\mathrm{PM}_{10}\left(211.0 \mu \mathrm{g} \mathrm{m}^{-3}\right)$. We also found a level particularly high and equal to $5.9 \mathrm{\mu g} \mathrm{m}^{-3}$ for OC in the $\mathrm{PM}_{10}$ fraction (see Figures S2a and S3a). 
Episode II is indicative for an extended forest wildfire (WF) spread over a large area around the location of our MCU station. This forest fire lasted for almost one month, August 2017, and coincided with particularly high records of the mass concentration of $\mathrm{PM}_{2.5}$ (about $47.0 \mu \mathrm{g} \mathrm{m}^{-3}$ ) and with the highest values recorded in the finer fraction for both the carbonaceous species: OC $\left(22.3 \mu \mathrm{g} \mathrm{m}^{-3}\right)$ and EC $\left(0.7 \mu \mathrm{g} \mathrm{m}^{-3}\right)$ (see Figures S2, S3, and S4, in the Supplementary Materials). The backward trajectories corresponding to 7 August 2017 (Figure $7 \mathrm{~b}$ (upper side)) illustrates the influence of westerly air masses. Apart from the air masses arriving from the west (W; with characteristically higher height), an air mass from a south-western (SW) direction with a lower elevation of origin reflects shorter-range transport. An NAAPS-based map, corresponding to this day and reported in Figure $7 \mathrm{~b}$ (lower side), shows that, at ground levels, and in correspondence of the area where MCU station is located, the model estimates a smoke concentration higher than $126 \mu \mathrm{g} \mathrm{m}^{-3}$.

The third quadrant in Figure 7 exemplifies Episode III, representative of BKG conditions, and refers to 14 November 2016, when we recorded for both PM and carbonaceous species concentrations, the lowest concentrations at the MCU station. The backward trajectories reported in Figure 7c (upper side) shows the influence of clean oceanic air masses coming from the north-north-west (NNW). Such event was primarily related to air masses coming from the free troposphere (backward-trajectories starting from 3000 to $6000 \mathrm{~m}$ a.s.l) and is likely to have resulted from a long-range transport. In addition, the map reported in Figure 7c (lower side), denotes the complete absence of both dust and smoke concentrations over the whole European territory.

Over the whole period of our observations, we marked as a BKG, WF, or NAF event each day showing similar characteristics to one of the above-described three episodes. We then separated the whole dataset in three sub-sets whose main descriptive statistics are summarized in Table S6.

Figure 8 specifically reports the average concentrations, along with the 5th and 95th percentiles, obtained separately over the whole dataset (TOT) and over the three sub-sets each including measurements done during the identified BKG, WF, or NAF events. In correspondence of BKG, as also highlighted in Table S6, all the parameters showed the lowest values. As summarized in Table 1, the BKG conditions prevailed during the fall season, coinciding with well-ventilated conditions, low photochemical activity, higher precipitation amounts, and less frequency of Saharan dust as well as wildfires episodes. Plots in Figure 8 show the PM levels and the OC and EC carbonaceous concentrations, distinguished for both fine and coarse mode. The figure highlights the influence of both wildfire emissions and Saharan dust over our measurements. It is in fact evident that the WF episodes affected mainly the finer fraction of the carbonaceous species with the highest averaged values recorded for $\mathrm{OC}_{\text {fine }}\left(2.2 \mu \mathrm{g} \mathrm{m}^{-3}\right)$ and for $\mathrm{EC}_{\text {fine }}\left(0.2 \mu \mathrm{g} \mathrm{m}^{-3}\right)$. Previous studies suggested that forest fires produce mainly fine-mode particle $[70,71]$. There is a large number of literature-based studies showing the increasing contribution of pyrogenic particles to fine carbonaceous aerosol [72-74].

The NAF episodes were indeed more impactful on the coarser mode, mainly for the OC species $\left(\mathrm{OC}_{\text {NAFcoarse }}=1.3 \mu \mathrm{g} \mathrm{m}^{-3}\right)$ and with particular emphasis on the mass concentration $\left(\mathrm{PM}_{\text {NAFcoarse }}=\right.$ $35.6 \mu \mathrm{g} \mathrm{m}^{-3}$ ). This value of PM concentration was five times higher than the corresponding averaged value obtained over WF influence $\left(\mathrm{PM}_{\mathrm{WF} \text { coarse }}=7.3 \mu \mathrm{g} \mathrm{m} \mathrm{m}^{-3}\right)$, and even almost ten-fold larger than that recorded in BKG conditions $\left(\mathrm{PM}_{\mathrm{BKG}} \mathrm{Barse}=3.9 \mu \mathrm{g} \mathrm{m}^{-3}\right)$. Very few data exist on measurements of OC and EC during Saharan dust episodes, or more generally on mineral aerosol. In the same way, laboratory studies on the topic are still scant [75]. For example, Goss and Eisenreich [76] and $\mathrm{Li}$ et al. [77] presented some evidence of adsorption of organic vapors on mineral dust. As OC is a mixture of hundreds of individual compounds spanning a wide range of chemical and thermodynamic properties, interaction between mineral dust and organic compounds depends on the amount and properties of each compound [78]. 

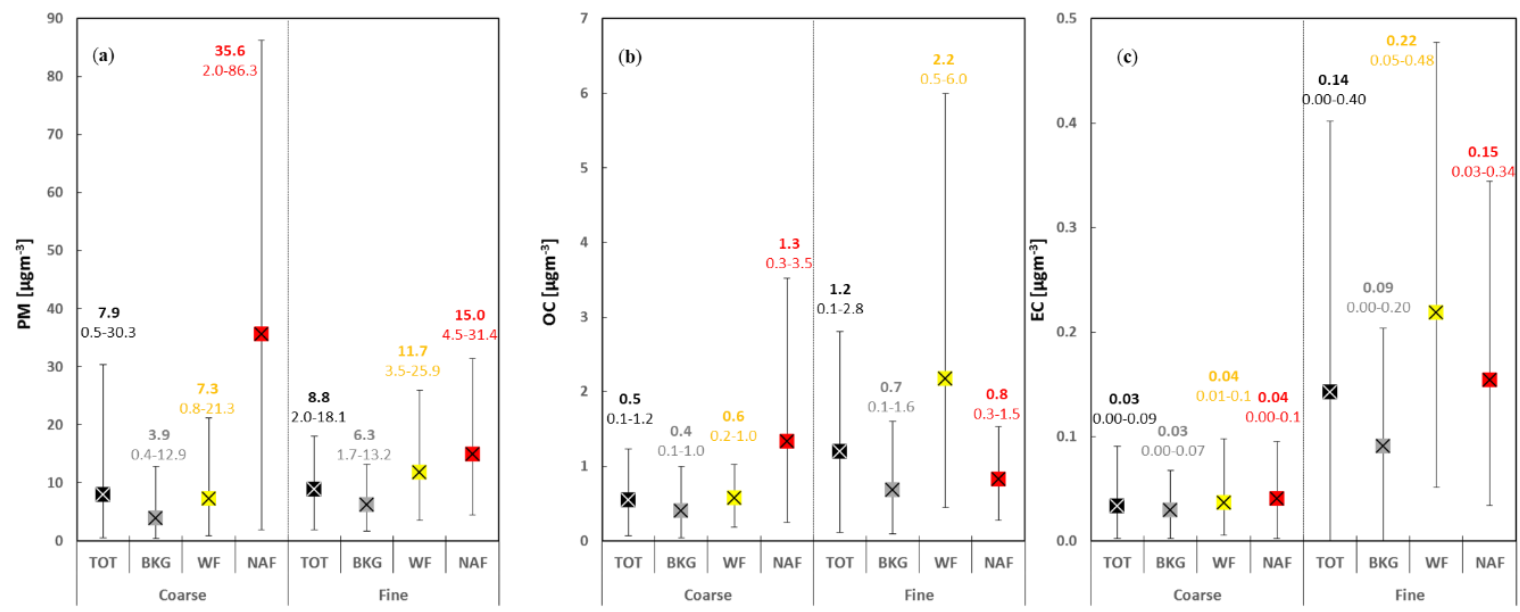

Figure 8. This figure shows mean levels (dots), 5th and 95th percentiles (whiskers) for: The whole dataset (TOT-black colour), for that containing only days identified as background (BKG-grey) conditions, that with days affected by wildfire (WF-yellow) events, and finally that for the North African Saharan dust (NAF-red) occurrences. We also distinguished between fine and coarse concentrations that are herein reported for (a) PM mass concentration; (b) OC; and (c) EC carbonaceous content.

\section{Conclusions}

In the present work, we presented simultaneous $\mathrm{PM}_{2.5}$ and $\mathrm{PM}_{10}$ measurements collected at the Monte Curcio station, within the Sila National Park, in southern Italy. We also reported the OC and EC content, analyzed over each sampled filter by the thermos-optical analysis. We investigated our results differentiating the fine particulate fraction from the coarser one. The fine and coarse mode OC and EC values reported in this work are the first long-term data published for the central-southern Mediterranean basin. We studied the local and long-term atmospheric patterns, with their influences, by using the Hysplit model coupled with satellite maps, like those provided by both NAAPS and FIRMS tools. Results evidenced the relevant impact of wildfire events and Saharan dust intrusion with respect to background conditions, during which the concentrations were found to be the lowest one for PM (coarse: $3.9 \pm 4.4 \mu \mathrm{g} \mathrm{m}^{-3}$; fine: $6.3 \pm 3.5 \mu \mathrm{g} \mathrm{m}^{-3}$ ), OC (coarse: $0.4 \pm 0.4 \mu \mathrm{g} \mathrm{m}^{-3}$; fine: $0.7 \pm 0.5 \mu \mathrm{g} \mathrm{m}^{-3}$ ), and EC (fine: $0.03 \pm 0.02 \mu \mathrm{g} \mathrm{m}^{-3}$; coarse: $0.09 \pm 0.07 \mu \mathrm{g} \mathrm{m}^{-3}$ ).

Due to the wide availability of vegetation and biomass in our area of investigation, and facilitated by the increase in temperatures, we found that wildfires in the summer period are a relevant source of PM, with particular impacting emphasis over the finer fraction. Levels recorded over the WF conditions raised in fact the following values for PM (coarse: $7.3 \pm 7.0 \mu \mathrm{g} \mathrm{m}^{-3}$; fine: $11.7 \pm 7.0 \mu \mathrm{g} \mathrm{m}^{-3}$ ), for OC (coarse: $0.6 \pm 0.3 \mu \mathrm{g} \mathrm{m}^{-3}$; fine: $2.2 \pm 2.4 \mu \mathrm{g} \mathrm{m}^{-3}$ ), and for EC (fine: $0.04 \pm 0.03 \mu \mathrm{g} \mathrm{m}^{-3}$; coarse: $\left.0.2 \pm 0.1 \mu \mathrm{gm}^{-3}\right)$.

Based on our observations, we found that the Saharan dust intrusions (NAF) occurred more often in the spring period, being associated with synoptic pattern characterized by an anticyclonic ridge extending from northern Africa to the southern Italian Peninsula. The NAF influence revealed a strong impact over the coarse mode, for the concentrations of PM (coarse: $35.6 \pm 31.7 \mu \mathrm{g} \mathrm{m}^{-3}$; fine: $15.0 \pm 10.4 \mu \mathrm{g} \mathrm{m}^{-3}$ ), and OC (coarse: $1.3 \pm 1.1 \mu \mathrm{g} \mathrm{m}^{-3}$; fine: $0.8 \pm 0.4 \mu \mathrm{g} \mathrm{m}^{-3}$ ). Because it is expected the Mediterranean basin will probably experience more frequent and severe droughts in the near future, as well as significant increasing in fire activity, such events might gain further importance as sources of atmospheric compounds are able to exert an influence on the regional climate and on the tropospheric composition over the Mediterranean basin.

Therefore, further research efforts are needed to investigate long-term trends of sources of fine and coarse PM fraction in the Southern Mediterranean area for air quality applications, for management of health risks, and for analysis of carbonaceous species impact to climate change in Mediterranean basin. A more in-depth investigation of the entire data set detected to date at the GAW regional Monte Curcio 
observatory, together with further efforts in atmospheric and climatic monitoring, will provide in the short term a useful and unique window in the central-southern Mediterranean region, recognized as one of the most reactive to air pollution and climate change.

Supplementary Materials: The following are available online at http://www.mdpi.com/2073-4433/10/10/592/s1, Table S1: Accuracy proved during the test report at the MCU (Monte Curcio) station for the sensors of: WS (wind speed), WD (wind direction), P (pressure), T (air temperature), and RH (relative humidity), Table S2: Descriptive statistics (min, mean, max) for each meteorological variable (RH, T, WD, WS, and P) recorded at MCU during 2016 and 2017 station and split by seasons of our PM measurements: Spring (April, May, June); Summer (July, August, September); Fall (October, November, December), Table S3: Name, Code, Coordinates, Altitude, Type, and References for those stations in the Mediterranean basin for which there are studies and data on air quality, Table S4: Descriptive statistics (min, mean, max, SD)computed over the complete observing period, and referring to Particulate Matter (PM), Organic Carbon (OC), Elemental Carbone (EC), ratio OC/EC, Secondary Organic Carbon (SOC), and percentage of SOC over OC, all determined for PM10, $\mathrm{PM}_{\text {fine }}$ and $\mathrm{PM}_{\text {coarse }}$ size fractions, Table S5: Descriptive statistics (min, mean, Max, SD)referring to the same parameters and for the same PM size fractions cited in Table S4 and herein discriminated by seasons: Spring, Summer, and Fall, Table S6: Descriptive statistics (min, mean, max, SD)referring to the same parameters and for the same PM size fractions cited in Table S4 and herein discriminated by the events: North African Saharan Dust (NAF), Wildfire (WF), and Background (BKG) conditions, Figure S1: Monthly trend of (a) $\mathrm{OC} / \mathrm{EC}_{2.5}$ ratio for the fine fraction, and (b) $\mathrm{OC} / \mathrm{EC}_{2.5-10}$ ratio for the coarse fraction recorded at the MCU Observatory since April to December 2016 and from April to December 2017. Each box includes the mean (midline), 25th and 75th percentiles (box edges), 5th and 95th percentiles (whiskers), Figure S2: Time-series recorded at the MCU station (a) $\mathrm{PM}_{10}$ and (b) $\mathrm{PM}_{2.5}$ observed over the whole sampling period and discriminated by the influencing events: Background (BKG-grey), Wildfire (WF-yellow), and North African Saharan Dust (NAF-red), Figure S3: Time-series recorded at the MCU station (a) OC 10 and (b) $\mathrm{OC}_{2.5}$ observed over the whole sampling period and discriminated by the influencing events: Background (BKG-grey), Wildfire (WF-yellow), and North African Saharan Dust (NAF-red), Figure S4: Time-series recorded at the MCU station (a) $\mathrm{EC}_{10}$ and (b) $\mathrm{EC}_{2.5}$ observed over the whole sampling period and discriminated by the influencing events: Background (BKG-grey), Wildfire (WF-yellow), and North African Saharan Dust (NAF-red).

Author Contributions: Conceptualization, M.B.; Data curation, F.D.A., S.M. and V. M.; Formal analysis, M.B., V.A., F.D.A., F.D.S. and J.C.; Investigation, M.B. and V. A.; Resources, V.M.; Software, F.D.A., A.N.; Supervision, F.S. and N.P.; Validation, F.D.A.; Visualization, F.D.A.; Writing-original draft, M.B.; Writing-review \& editing, Francesco De Simone and J.C. All authors participated in revising the article and gave their final approval of the version to be submitted.

Funding: "This research was funded by I-AMICA (Infrastructure of High Technology for Environmental and Climate Monitoring-PONa3_00363), a project of structural improvement financed under the National Operational Program (NOP) for "Research and Competitiveness 2007-2013" co-funded with the European Regional Development Fund (ERDF) and National resources.

Acknowledgments: The authors would like to acknowledge the NOAA Air Resources Laboratory (ARL) for providing the HYSPLIT transport and dispersion model, and of the READY Web site (http://www.arl.noaa.gov/ ready.html), whose results are used in this publication. The NCEP-based images are provided by the NOAA-CIRES Climate Diagnostics Center, Boulder, Colorado, USA, from their Web site at http://www.cdc.noaa.gov/, whereas the MODIS “Hotspot” data are from the MODIS Rapid Response System-Web Fire Mapper (http://maps.geog.umd.edu).

Conflicts of Interest: The authors declare no conflict of interest.

\section{References}

1. Raes, F. Formation and Cycling of Aerosols in the Global Troposphere. In Developments in Environmental Science; Elsevier: Amsterdam, The Netherland, 2002; Volume 1, pp. 519-563.

2. Paoletti, L. Physico-chemical characterisation of the inhalable particulate matter (PM10) in an urban area: An analysis of the seasonal trend. Sci. Total. Environ. 2002, 292, 265-275. [CrossRef]

3. Kanakidou, M.; Seinfeld, J.H.; Pandis, S.N.; Barnes, I.; Dentener, F.J.; Facchini, M.C.; Van Dingenen, R.; Ervens, B.; Nenes, A.; Nielsen, C.J.; et al. Organic aerosol and global climate modelling: A review. Atmos. Chem. Phys. Discuss. 2004, 4, 5855-6024. [CrossRef]

4. Putaud, J.P.; Van Dingenen, R.; Alastuey, A.; Bauer, H.; Birmili, W.; Cyrys, J.; Flentje, H.; Fuzzi, S.; Gehrig, R.; Hansson, H.; et al. A European aerosol phenomenology—3: Physical and chemical characteristics of particulate matter from 60 rural, urban, and kerbside sites across Europe. Atmos. Environ. 2010, 44, 1308-1320. [CrossRef]

5. Merico, E.; Cesari, D.; Dinoi, A.; Gambaro, A.; Barbaro, E.; Guascito, M.R.; Giannossa, L.C.; Mangone, A.; Contini, D. Inter-comparison of carbon content in PM10 and PM2.5 measured with two thermo-optical protocols on samples collected in a Mediterranean site. Environ. Sci. Pollut. Res. 2019, 26, 1-17. [CrossRef] [PubMed] 
6. Singh, A.; Rajput, P.; Sharma, D.; Sarin, M.M.; Singh, D. Black Carbon and Elemental Carbon from Postharvest Agricultural-Waste Burning Emissions in the Indo-Gangetic Plain. Adv. Meteorol. 2014, 2014, 1-10. [CrossRef]

7. Knaapen, A.M.; Borm, P.J.; Albrecht, C.; Schins, R.P. Inhaled particles and lung cancer. Part A: Mechanisms. Int. J. Cancer 2004, 109, 799-809. [CrossRef] [PubMed]

8. Vedal, S. Ambient Particles and Health: Lines that Divide. J. Air Waste Manag. Assoc. 1997, 47, 551-581. [CrossRef] [PubMed]

9. Blanchard, C.L.; Hidy, G.M.; Tanenbaum, S.; Edgerton, E.; Hartsell, B.; Jansen, J. Carbon in southeastern U.S. aerosol particles: Empirical estimates of secondary organic aerosol formation. Atmos. Environ. 2008, 42, 6710-6720. [CrossRef]

10. Sandrini, S.; Fuzzi, S.; Piazzalunga, A.; Prati, P.; Bonasoni, P.; Cavalli, F.; Bove, M.C.; Calvello, M.; Cappelletti, D.; Colombi, C.; et al. Spatial and seasonal variability of carbonaceous aerosol across Italy. Atmos. Environ. 2014, 99, 587-598. [CrossRef]

11. Querol, X.; Alastuey, A.; Pey, J.; Cusack, M.; Perez, N.; Mihalopoulos, N.; Theodosi, C.; Gerasopoulos, E.; Kubilay, N.; Koçak, M. Variability in regional background aerosols within the Mediterranean. Atmos. Chem. Phys. Discuss. 2009, 9, 10153-10192. [CrossRef]

12. Pey, J.; Querol, X.; Alastuey, A. Variations of levels and composition of PM10 and PM2.5 at an insular site in the Western Mediterranean. Atmos. Res. 2009, 94, 285-299. [CrossRef]

13. Koulouri, E.; Saarikoski, S.; Theodosi, C.; Markaki, Z.; Gerasopoulos, E.; Kouvarakis, G.; Makela, T.; Hillamo, R.; Mihalopoulos, N. Chemical composition and sources of fine and coarse aerosol particles in the Eastern Mediterranean. Atmos. Environ. 2008, 42, 6542-6550. [CrossRef]

14. Pace, G.; Di Sarra, A.; Meloni, D.; Piacentino, S.; Chamard, P. Aerosol optical properties at Lampedusa (Central Mediterranean). 1. Influence of transport and identification of different aerosol types. Atmos. Chem. Phys. Discuss. 2006, 6, 697-713. [CrossRef]

15. Amato, F.; Alastuey, A.; Karanasiou, A.; Lucarelli, F.; Nava, S.; Calzolai, G.; Alves, C. AIRUSE-LIFE+: A harmonized PM speciation and source apportionment in five southern European cities. Atmos. Chem. Phys. 2016, 16, 3289-3309. [CrossRef]

16. Brunekreef, B. Epidemiological evidence of effects of coarse airborne particles on health. Eur. Respir. J. 2005, 26, 309-318. [CrossRef] [PubMed]

17. Schultz, M.G.; Akimoto, H.; Bottenheim, J.; Buchmann, B.; Galbally, I.E.; Gilge, S.; Helmig, D.; Koide, H.; Lewis, A.C.; Novelli, P.C.; et al. The Global Atmosphere Watch reactive gases measurement network. Elem. Sci. Anth. 2015, 3, 67. [CrossRef]

18. Schürmann, G.; Algieri, A.; Hedgecock, I.; Manna, G.; Pirrone, N.; Sprovieri, F. Modelling local and synoptic scale influences on ozone concentrations in a topographically complex region of Southern Italy. Atmos. Environ. 2009, 43, 4424-4434. [CrossRef]

19. Collaud Coen, M.; Andrews, E.; Aliaga, D.; Andrade, M.; Angelov, H.; Bukowiecki, N.; Ealo, M.; Fialho, P.; Flentje, H.; Hallar, A.G.; et al. Identification of topographic features influencing aerosol observations at high altitude stations. Atmos. Chem. Phys. 2018, 18, 12289-12313. [CrossRef]

20. UNI EN 12341. Ambient Air-Standard Gravimetric Measurement Method for the Determination of the PM10 or PM2,5 Mass Concentration of Suspended Particulate Matter. Available online: http://store.uni.com/catalogo/ index.php/en-12341-2014.html (accessed on 30 May 2016).

21. Perrino, C. Comparing the Performance of Teflon and Quartz Membrane Filters Collecting Atmospheric PM: Influence of Atmospheric Water. Aerosol Air Qual. Res. 2013, 13, 137-147. [CrossRef]

22. EMEP Manual for Sampling and Analysis, EMEP/CCC Report 1/95, Revision 1/2002. Available online: http://www.nilu.no/projects/ccc/manual/index.html (accessed on 14 November 2015).

23. Sunset Laboratory Inc. Semi-Continuous OC/EC carbon aerosol Analyzer. In A Guide to Running and Maintaining the Sunset Laboratory Semi-Continuous OC/EC Analyzer; Sunset Laboratory Inc.: Portland, OR, USA. Available online: https://www3.epa.gov/ttnamti1/files/ambient/pm25/spec/Sunset_Manual.pdf (accessed on 10 June 2015).

24. EN 16909. Ambient Air-Measurement of Elemental Carbon (EC) and Organic Carbon (OC) Collected on Filters. 2017. Available online: http://store.uni.com/catalogo/index.php/en-16909-2017.html (accessed on 20 May 2018).

25. Cavalli, F.; Putaud, J.; Viana, M.; Yttri, K.; Genberg, J.; Toward, A. Standardised Thermal-Optical Protocol for Measuring Atmospheric Organic and Elemental Carbon: The EUSAAR Protocol. Atmos. Meas. Tech. 2010, 3 , 79-89. [CrossRef] 
26. Castro, L.M.; Pio, C.A.; Harrison, R.M.; Smith, D.J.T. Carbonaceous Aerosol in Urban and Rural European Atmospheres: Estimation of Secondary Organic Carbon Concentrations. Atmos. Environ. 1999, 33, 2771-2781. [CrossRef]

27. Dinoi, A.; Cesari, D.; Marinoni, A.; Bonasoni, P.; Riccio, A.; Chianese, E.; Tirimberio, G.; Naccarato, A.; Sprovieri, F.; Andreoli, V.; et al. Inter-Comparison of Carbon Content in PM2.5 and PM10 Collected at Five Measurement Sites in Southern Italy. Atmosphere 2017, 8, 243. [CrossRef]

28. Turpin, B.J.; Huntzicker, J.J. Secondary formation of organic aerosol in the Los Angeles basin: A descriptive analysis of organic and elemental carbon concentrations. Atmos. Environ. Part A Gen. Top. 1991, 25, 207-215. [CrossRef]

29. Lim, H.J.; Turpin, B.J. Origins of primary and secondary organic aerosol in Atlanta: Results of time-resolved measurements during the Atlanta Supersite Experiment. Environ. Sci. Technol. 2002, 36, 4489-4496. [CrossRef] [PubMed]

30. Cabada, J.C.; Pandis, S.N.; Subramanian, R.; Robinson, A.L.; Polidori, A.; Turpin, B. Estimating the Secondary Organic Aerosol Contribution to PM 2.5 Using the EC Tracer Method Special Issue of Aerosol Science and Technology on Findings from the Fine Particulate Matter Supersites Program. Aerosol Sci. Technol. 2004, 38, 140-155. [CrossRef]

31. Harrison, R.M.; Yin, J. Sources and processes affecting carbonaceous aerosol in central England. Atmos. Environ. 2008, 42, 1413-1423. [CrossRef]

32. Pio, C.; Cerqueira, M.; Harrison, R.M.; Nunes, T.; Mirante, F.; Alves, C.; Oliveira, C.; De La Campa, A.S.; Artínano, B.; Matos, M.; et al. OC/EC ratio observations in Europe: Re-thinking the approach for apportionment between primary and secondary organic carbon. Atmos. Environ. 2011, 45, 6121-6132. [CrossRef]

33. Turpin, B.J.; Huntzicker, J.J. Identification of secondary organic aerosol episodes and quantitation of primary and secondary organic aerosol concentrations during SCAQS. Atmos. Environ. 1995, 29, 3527-3544. [CrossRef]

34. Carslaw, D.C.; Ropkins, K. Openair-An R package for air quality data analysis. Environ. Model. Softw. 2012, 27, 52-61. [CrossRef]

35. Secretary-General of the European Commission. Commission Staff Working Paper Establishing Guidelines for Demonstration and Subtraction of Exceedances Attributable to Natural Sources under the Directive 2008/50/EC on Ambient Air Quality and Cleaner Air for Europe; European Commission: Brussels, Belgium, 2011.

36. Rodríguez, S.; Querol, X.; Alastuey, A.; Kallos, G.; Kakaliagou, O. Saharan dust contributions to PM10 and TSP levels in Southern and Eastern Spain. Atmos. Environ. 2001, 35, 2433-2447. [CrossRef]

37. Escudero, M.; Castillo, S.; Querol, X.; Avila, A.; Alarcon, M.; Viana, M.M.; Alastuey, A.; Cuevas, E.; Rodríguez, S. Wet and dry African dust episodes over eastern Spain. J. Geophys. Res. Space Phys. 2005, 110, D18S08. [CrossRef]

38. Escudero, M.; Querol, X.; Pey, J.; Alastuey, A.; Perez, N.; Ferreira, F.; Alonso, S.; Rodríguez, S.; Cuevas, E. A methodology for the quantification of the net African dust load in air quality monitoring networks. Atmos. Environ. 2007, 41, 5516-5524. [CrossRef]

39. Querol, X.; Pey, J.; Pandolfi, M.; Alastuey, A.; Cusack, M.; Perez, N.; Moreno, T.; Viana, M.; Mihalopoulos, N.; Kallos, G.; et al. African dust contributions to mean ambient PM10 mass-levels across the Mediterranean Basin. Atmos. Environ. 2009, 43, 4266-4277. [CrossRef]

40. Pey, J.; Alastuey, A.; Querol, X.; Pérez, N.; Cusack, M. A simplified approach to the indirect evaluation of the chemical composition of atmospheric aerosols from PM mass concentrations. Atmos. Environ. 2010, 44, 5112-5121. [CrossRef]

41. Draxler, R.R.; Rolph, G.D. HYSPLIT (Hybrid Single-Particle Lagrangian Integrated Trajectory) Model Access via NOAA ARL Ready Website; NOAA Air Resources Laboratory: College Park, MD, USA, 2013. Available online: http://www.arl.noaa.gov/HYSPLIT.php (accessed on 24 February 2014).

42. Febo, A.; Guglielmi, F.; Manigrasso, M.; Ciambottini, V.; Avino, P. Local Air Pollution and Long-Range Mass Transport of Atmospheric Particulate Matter: A Comparative Study of the Temporal Evolution of the Aerosol Size Fractions. Atmos. Pollut. Res. 2010, 1, 141-146. [CrossRef]

43. Hussein, T.; Karppinen, A.; Kukkonen, J.; Härkönen, J.; Aalto, P.P.; Hämeri, K.; Kerminen, V.M.; Kulmala, M. Meteorological dependence of size-fractionated number concentrations of urban aerosol particles. Atmos. Environ. 2006, 40, 1427-1440. [CrossRef] 
44. Hussein, T. Local Air Pollution versus Short-range Transported Dust Episodes: A Comparative Study for Submicron Particle Number Concentration. Aerosol Air Qual. Res. 2011, 11, 109-119. [CrossRef]

45. Kgabi, N.A.; Mokgwetsi, T. Dilution and dispersion of inhalable particulate matter. WIT Trans. Ecol. Environ. 2009, 127, 229-238.

46. EC. Directive 2008/50/EC of the European Parliament and of the Council of 21 May 2008 on ambient air quality and a cleaner air for Europe. EC Off. J. Eur. Union. L 2008, 152, 1-44.

47. Perrone, M.G.; Larsen, B.R.; Ferrero, L.; Sangiorgi, G.; De Gennaro, G.; Udisti, R.; Bolzacchini, E. Sources of high PM2. 5 concentrations in Milan, Northern Italy: Molecular marker data and CMB modelling. Sci. Total Environ. 2012, 414, 343-355. [CrossRef]

48. Cristofanelli, P.; Fierli, F.; Marinoni, A.; Calzolari, F.; Duchi, R.; Burkhart, J.; Bonasoni, P. Influence of biomass burning and anthropogenic emissions on ozone, carbon monoxide and black carbon at the Mt. Cimone GAW-WMO global station (Italy, $2165 \mathrm{~m}$ asl). Atmos. Chem. Phys. 2013, 13, 15-30. [CrossRef]

49. Dayan, U.; Heffter, J.L.; Miller, J.M. Meteorological and climatological data from surface and upper measurements for the assessment of atmospheric transport and deposition of pollutants in the Mediterranean Basin: Part B: Seasonal distribution of the planetary boundary layer depths over the Mediterranean Basin, UNEP. In Mediterranean Action Plan Technical Reports Series; UNEP: Denmark, Copenhagen, 1989.

50. De La Campa, A.M.S.; Pio, C.; De La Rosa, J.D.; Querol, X.; Alastuey, A.; González-Castanedo, Y. Characterization and origin of EC and OC particulate matter near the Doñana National Park (SW Spain). Environ. Res. 2009, 109, 671-681. [CrossRef] [PubMed]

51. Lonati, G.; Ozgen, S.; Giugliano, M. Primary and secondary carbonaceous species in PM2.5 samples in Milan (Italy). Atmos. Environ. 2007, 41, 4599-4610. [CrossRef]

52. Na, K.; Sawant, A.A.; Song, C.; Cocker, D.R. Primary and secondary carbonaceous species in the atmosphere of Western Riverside County, California. Atmos. Environ. 2004, 38, 1345-1355. [CrossRef]

53. Cachier, H.; Brémond, M.P.; Buat-Ménard, P. Carbonaceous aerosols from different tropical biomass burning sources. Nature 1989, 340, 371-373. [CrossRef]

54. Yang, F.; He, K.; Ye, B.; Chen, X.; Cha, L.; Cadle, S.H.; Chan, T.; Mulawa, P.A. One-year record of organic and elemental carbon in fine particles in downtown Beijing and Shanghai. Atmos. Chem. Phys. Discuss. 2005, 5, 1449-1457. [CrossRef]

55. Capra, A.; Consoli, S.; Scicolone, B. Long-term climatic variability in Calabria and effects on drought and agrometeorological parameters. Water Resour. Manag. 2013, 27, 601-617. [CrossRef]

56. Cugerone, K.; De Michele, C.; Ghezzi, A.; Gianelle, V. Aerosol removal due to precipitation and wind forcings in Milan urban area. J. Hydrol. 2018, 556, 1256-1262. [CrossRef]

57. Laakso, L. Ultrafine particle scavenging coefficients calculated from 6 years field measurements. Atmos. Environ. 2003, 37, 3605-3613. [CrossRef]

58. Mircea, M.; Ştefan, S.; Fuzzi, S. Precipitation scavenging coefficient: Influence of measured aerosol and raindrop size distributions. Atmos. Environ. 2000, 34, 5169-5174. [CrossRef]

59. Chate, D.; Pranesha, T. Field studies of scavenging of aerosols by rain events. J. Aerosol Sci. 2004, 35, 695-706. [CrossRef]

60. Maria, S.F.; Russell, L.M. Organic and inorganic aerosol below-cloud scavenging by suburban New Jersey precipitation. Environ. Sci. Technol. 2005, 39, 4793-4800. [CrossRef]

61. Andronache, C.; Grönholm, T.; Laakso, L.; Phillips, V.; Venäläinen, A. Scavenging of ultrafine particles by rainfall at a boreal site: Observations and model estimations. Atmos. Chem. Phys. Discuss. 2006, 6, 3801-3844. [CrossRef]

62. Zikova, N.; Zdimal, V. Precipitation scavenging of aerosol particles at a rural site in the Czech Republic. Tellus B Chem. Phys. Meteorol. 2016, 68, 2477. [CrossRef]

63. Cristofanelli, P.; Landi, T.C.; Calzolari, F.; Duchi, R.; Marinoni, A.; Rinaldi, M.; Bonasoni, P. Summer atmospheric composition over the Mediterranean basin: Investigation on transport processes and pollutant export to the free troposphere by observations at the WMO/GAW Mt. Cimone global station (Italy, $2165 \mathrm{~m}$ asl). Atmos. Environ. 2016, 141, 139-152. [CrossRef]

64. Zellweger, C.; Ammann, M.; Buchmann, B.; Hofer, P.; Lugauer, M.; Rüttimann, R.; Baltensperger, U. Summertime NO y speciation at the Jungfraujoch, $3580 \mathrm{~m}$ above sea level, Switzerland. J. Geophys. Res.Atmos. 2000, 105, 6655-6667. [CrossRef] 
65. Sahu, L.K.; Kondo, Y.; Miyazaki, Y.; Pongkiatkul, P.; Oanh, N.T.K. Seasonal and diurnal variations of black carbon and organic carbon aerosols in Bangkok. J. Geophys. Res. Space Phys. 2011, 116. [CrossRef]

66. Cristofanelli, P.; Marinoni, A.; Arduini, J.; Bonafé, U.; Calzolari, F.; Colombo, T.; Decesari, S.; Duchi, R.; Facchini, M.C.; Fierli, F.; et al. Significant variations of trace gas composition and aerosol properties at Mt. Cimone during air mass transport from North Africa-Contributions from wildfire emissions and mineral dust. Atmos. Chem. Phys. Discuss. 2009, 9, 4603-4619. [CrossRef]

67. Papayannis, A.; Amiridis, V.; Mona, L.; Tsaknakis, G.; Balis, D.; Bösenberg, J.; Chaikovski, A.; De Tomasi, F.; Grigorov, I.; Mattis, I.; et al. Systematic lidar observations of Saharan dust over Europe in the frame of EARLINET (2000-2002). J. Geophys. Res. Space Phys. 2008, 113. [CrossRef]

68. Marinoni, A.; Cristofanelli, P.; Calzolari, F.; Roccato, F.; Bonafè, U.; Bonasoni, P. Continuous measurements of aerosol physical parameters at the Mt. Cimone GAW Station (2165ma.s.l., Italy). Sci. Total Environ. 2008, 391, 241-251. [CrossRef]

69. Coen, M.C.; Weingartner, E.; Schaub, D.; Hueglin, C.; Corrigan, C.; Henning, S.; Schwikowski, M.; Baltensperger, U. Saharan dust events at the Jungfraujoch: Detection by wavelength dependence of the single scattering albedo and first climatology analysis. Atmos. Chem. Phys. Discuss. 2004, 4, 2465-2480. [CrossRef]

70. Ward, T.J.; Hamilton, R.F., Jr.; Dixon, R.W.; Paulsen, M.; Simpson, C.D. Characterization and evaluation of smoke tracers in PM: Results from the 2003 Montana wildfire season. Atmos. Environ. 2006, 40, 7005-7017. [CrossRef]

71. Pio, C.; Legrand, M.; Alves, C.; Oliveira, T.S.; Afonso, J.; Caseiro, A.; Puxbaum, H.; Sanchez-Ochoa, A.; Gelencsér, A.; Pio, C.; et al. Chemical composition of atmospheric aerosols during the 2003 summer intense forest fire period. Atmos. Environ. 2008, 42, 7530-7543. [CrossRef]

72. Gilardoni, S.; Vignati, E.; Marmer, E.; Cavalli, F.; Belis, C.; Gianelle, V.; Loureiro, A.; Artaxo, P. Sources of carbonaceous aerosol in the Amazon basin. Atmos. Chem. Phys. Discuss. 2011, 11, 2747-2764. [CrossRef]

73. Decesari, S.; Fuzzi, S.; Facchini, M.C.; Mircea, M.; Emblico, L.; Cavalli, F.; Maenhaut, W.; Chi, X.; Schkolnik, G.; Falkovich, A.; et al. Characterization of the organic composition of aerosols from Rondônia, Brazil, during the LBA-SMOCC 2002 experiment and its representation through model compounds. Atmos. Chem. Phys. Discuss. 2006, 6, 375-402. [CrossRef]

74. Andreae, M.O. Soot carbon and excess fine potassium: Long-range transport of combustion-derived aerosols. Science 1983, 220, 1148-1151. [CrossRef]

75. Usher, C.R.; Michel, A.E.; Grassian, V.H. Reactions on mineral dust. Chem. Rev. 2003, 103, 4883-4940. [CrossRef] [PubMed]

76. Goss, K.U.; Eisenreich, S.J. Adsorption of VOCs from the Gas Phase to Different Minerals and a Mineral Mixture. Environ. Sci. Technol. 1996, 30, 2135-2142. [CrossRef]

77. Li, P.; Perreau, K.A.; Covington, E.; Song, C.H.; Carmichael, G.R.; Grassian, V.H. Heterogeneous reactions of volatile organic compounds on oxide particles of the most abundant crustal elements: Surface reactions of acetaldehyde, acetone, and propionaldehyde on $\mathrm{SiO} 2, \mathrm{Al} 2 \mathrm{O} 3, \mathrm{Fe} 2 \mathrm{O} 3, \mathrm{TiO} 2$, and $\mathrm{CaO}$. J. Geophys. Res. Space Phys. 2001, 106, 5517-5529. [CrossRef]

78. Turpin, B.J.; Saxena, P.; Andrews, E. Measuring and simulating particulate organics in the atmosphere: Problems and prospects. Atmos. Environ. 2000, 34, 2983-3013. [CrossRef]

(C) 2019 by the authors. Licensee MDPI, Basel, Switzerland. This article is an open access article distributed under the terms and conditions of the Creative Commons Attribution (CC BY) license (http://creativecommons.org/licenses/by/4.0/). 